\title{
ECONOMIC ANALYSIS OF GRID LEVEL ENERGY STORAGE FOR THE APPLICATION OF LOAD LEVELING
}

\author{
by \\ Robert John Kerestes \\ B.S. in Electrical Engineering \\ University of Pittsburgh, 2010
}

\author{
Submitted to the Graduate Faculty of \\ Swanson School of Engineering in partial fulfillment \\ of the requirements for the degree of \\ Master of Science
}

University of Pittsburgh 


\section{UNIVERSITY OF PITTSBURGH \\ SWANSON SCHOOL OF ENGINEERING}

This thesis was presented

by

Robert John Kerestes

It was defended on

September 23, 2011

and approved by

George Kusic, Ph.D., Associate Professor, Electrical and Computer Engineering Department Zhi-Hong Mao, Ph.D., Associate Professor, Electrical and Computer Engineering Department

Marlin Mickle, Ph.D., Professor, Electrical and Computer Engineering Department Thesis Advisor: Gregory F. Reed, Ph.D., Associate Professor, Electrical and Computer Engineering Department 
Copyright (c) by Robert J. Kerestes

2011 


\title{
ECONOMIC ANALYSIS OF GRID LEVEL ENERGY STORAGE FOR THE APPLICATION OF LOAD LEVELING
}

\author{
Robert Kerestes, M.S.
}

University of Pittsburgh, 2011

The benefits that exist on behalf of energy storage appear to be nearly limitless and there is no exception to this in power systems. Energy storage can be used to flatten an electrical load by charging the storage when the system load is low and discharging the storage when the system load is high. This technique is known as load leveling and is the storage application of interest in this thesis.

One of the biggest benefits that load leveling can yield is the elimination of expensive gas turbine generators. Gas turbine generators are used because they can react to drastic changes in the system load that other generators can't. Their downfall however, is that they are more expensive than the other generators. But if the load is level enough, there is no need to use gas turbine generators because there aren’t any drastic changes in the load.

Load leveling requires a storage device to have a very large capacity. In this thesis several different large storage types are studied to see which ones are best suited for the application of load leveling. Ultimately both $\mathrm{NaS}$ batteries and pumped hydro storage are chosen to use for this study and the results for each is compared.

A theoretical double peak system load with a peak value of 1950 megawatts is used for this study. The load is leveled by discretizing the energy storage's charging and discharging profiles and allocating the stored energy by means of dynamic programming. An economic analysis of both the original case and the case in which energy storage is used to level the load is carried out. 
This study shows that energy storage used for the application of load leveling can be economically beneficial depending on the type of storage that is used. Battery storage is not quite ready to be used for this application but with some improvements to the technology it could be soon. Pumped storage on the other hand is the cheapest form grid level energy storage and can generate a great deal of economic gain in today’s power systems. 
TABLE OF CONTENTS

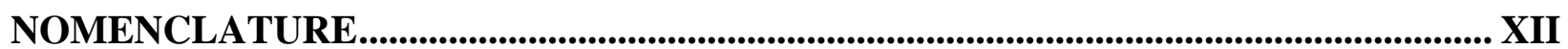

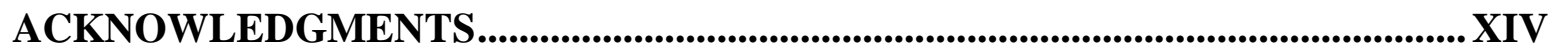

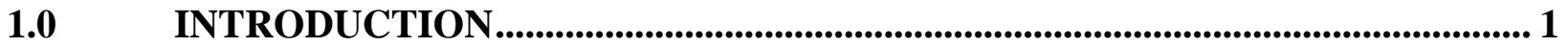

PROBLEM STATEMENT AND MOTIVATION ......................................... 2

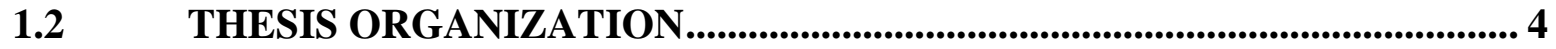

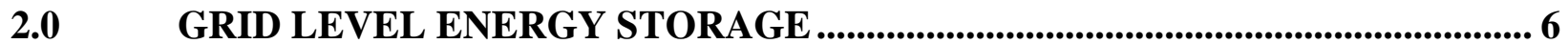

2.1 PEAK SHAVING VS. LOAD LEVELING ................................................ 6

2.1.1 Peak Shaving ....................................................................................................... 7

2.1.2 Load Leveling......................................................................................... 8

2.2 TYPES OF ENERGY STORAGE .......................................................... 9

2.2.1 Sodium Sulfur Batteries................................................................................. 10

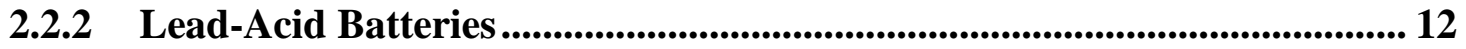

2.2.3 Flow Batteries .............................................................................................. 13

2.2.4 Pumped Storage .......................................................................................... 15

2.2.5 Compressed Air Energy Storage......................................................... 16

2.3 DISTRIBUTED ENERGY STORAGE SYSTEMS .................................... 19 
3.0 OPTIMIZATION OF THERMAL GENERATION UNITS AND ENERGY

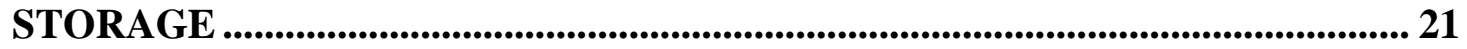

T.1 THE ECONOMIC DISPATCH PROBLEM .................................................... 21

3.1.1 Lagrange Multipliers and the Method of Optimization................................. 22

3.1.2 Solution to Thermal Generating Units Using Lagrange Multipliers........ 24

3.1.3 Economic Dispatch With Transmission Losses .............................................. 29

3.2 OPTIMIZING ENERGY STORAGE WITH DYNAMIC PROGRAMING31

3.2.1 Dynamic Programming Application in Power Systems................................ 33

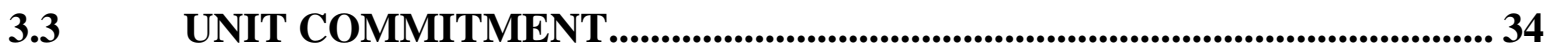

3.3.1 Maximum or Minimum Change in Output Power.......................................... 35

3.3.2 Start-Up Time ....................................................................................................... 35

3.3.3 Spinning Reserve …................................................................................................ 35

3.3.4 Minimum Up and Down Times ........................................................................ 36

4.0 PROBLEM SETUP AND SOLUTION .................................................................. 37

4.1 THERMAL GENERATION UNITS ................................................................... 39

$4.2 \quad$ SETTING UP THE UNIT COMMITMENT ...................................................... 41

4.3 MODELING THE SYSTEM LOAD ............................................................. 42

4.4 MODELING THE ENERGY STORAGE............................................................ 45

4.5 ALLOCATION OF STORAGE FOR LOAD LEVELING.............................. 53

4.6 SETTING UP THE ECONOMIC DISPATCH PROBLEM ........................... 57

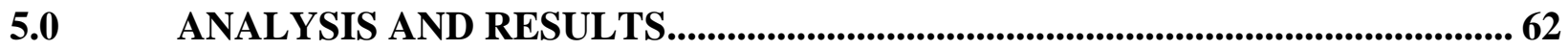


5.1 ECONOMIC DISPATCH SOLUTION WITHOUT ENERGY STORAGE 62

5.2 ECONOMIC DISPATCH SOLUTION WITH ENERGY STORAGE........ 67

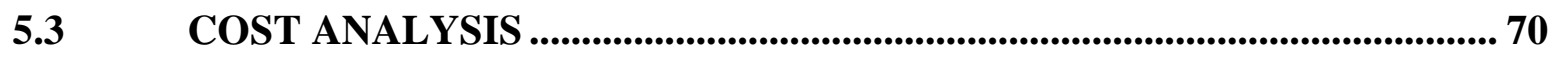

5.3.1 The Case with No Energy Storage ..................................................................... 72

5.3.2 The Case with Energy Storage .............................................................................. 72

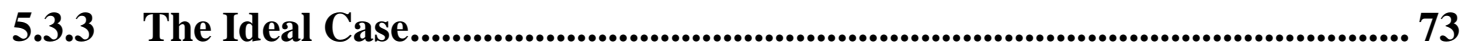

5.3.4 Storage Cost .......................................................................................................... 74

5.3.4.1 Cost of the NaS System........................................................................ 74

5.3.4.2 Cost of the Pumped Storage Facility ....................................................... 74

5.3.5 Economic Feasibility and Comparative Analysis ........................................... 75

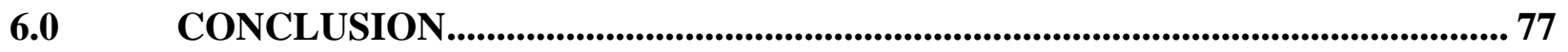

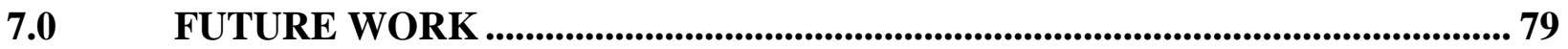

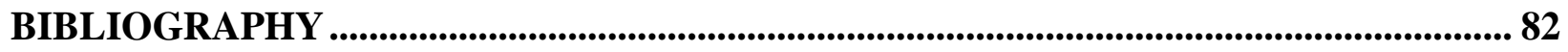




\section{LIST OF TABLES}

Table 4-1: Pollutants Generated By Fossil Fuel Electricity Generation [32] ............................ 38

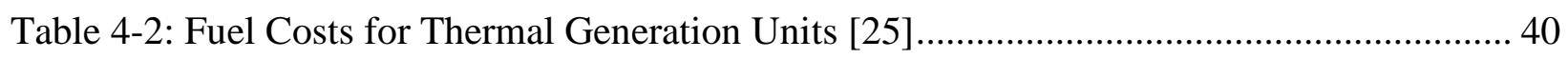

Table 4-8: Gas Turbine Generation Unit Commitment Constraints [25] ................................. 41

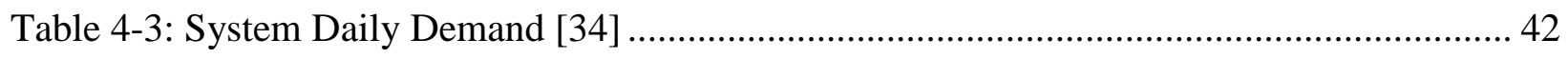

Table 4-4: Feasibility Scores of Grid Level Batteries [1] ................................................. 45

Table 4-5: Average Discharging Power Per Hour ............................................................... 51

Table 4-6: Effect of Storage on the System Load ................................................................. 55

Table 4-7: Discharging Times for the Commercial and Residential Batteries .......................... 57

Table 5-1: Power Distribution for Generators without Energy Storage .................................... 65

Table 5-2: Power Distribution of Generators with Energy Storage......................................... 68

Table 5-3: Daily Cost of Generation without Energy Storage................................................ 72

Table 5-4: Daily Cost of Generation with Energy Storage ................................................... 72

Table 5-5: Hourly Economic Dispatch for the Ideal Case ...................................................... 73

Table 5-6: Cost of Generation for the Ideal Case ….......................................................... 73 


\section{LIST OF FIGURES}

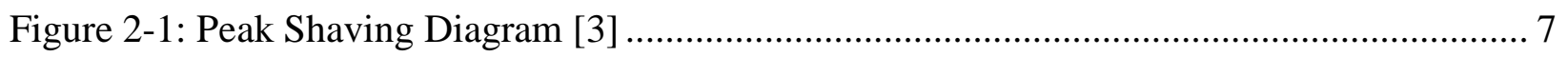

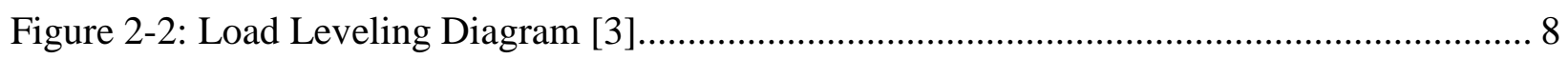

Figure 2-3: Positioning of Energy Storage Technologies [6] .............................................. 9

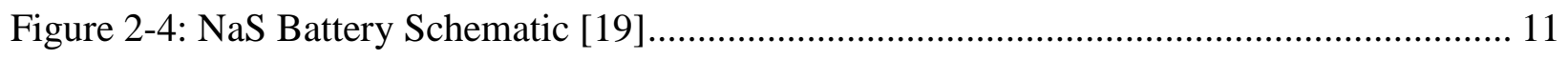

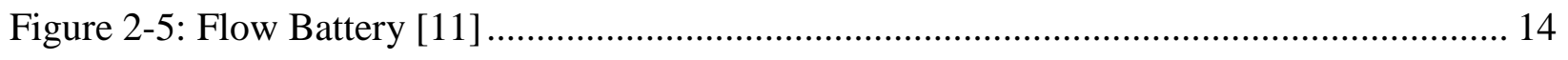

Figure 2-6: Raccoon Mountain Pumped-Storage Plants [18] ................................................ 15

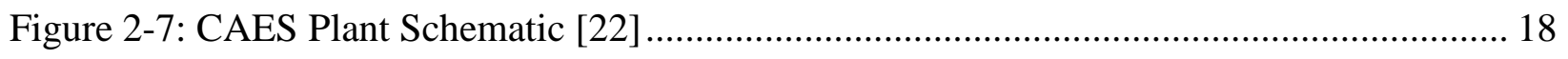

Figure 2-8: DESS Used for Grid Maintenance [1] ........................................................... 20

Figure 3-1: Graphical representation of optimal solution using the Lagrange multipliers [24] ... 24

Figure 3-2: Dispatch to a Load with $n$ Thermal Generators [25] ............................................ 25

Figure 3-3: Dispatch to a Load with $n$ Generators and Transmission Losses ........................... 30

Figure 3-4: Example of a Dynamic Programming Problem [25] ............................................ 32

Figure 3-5: Allocation of Energy Storage by Dynamic Programming [37] ............................... 34

Figure 4-1: Economic Dispatch Problem with Coal, Oil and Gas Thermal Generators and the Integration of Energy Storage ................................................................... 37

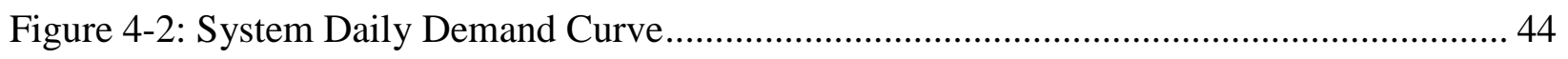

Figure 4-3: Feasibility Diagram of Grid Level Batteries [1] ................................................ 46

Figure 4-4: Charging and Discharging Profiles for 1 MW NaS Battery [1] ............................. 47 
Figure 4-5: Discharging Profile as a Piecewise Function of Power vs. Time 48

Figure 4-6: Discharging Profile for 45\% Depth of Discharge .............................................. 49

Figure 4-7: Average Power for Discharging Profiles ........................................................ 52

Figure 4-8: Charging and Discharge Profile for Energy Storage ......................................... 55

Figure 4-9: Load Profile Comparisons with the Integration of Storage .................................. 56

Figure 5-1: Power Distribution without Energy Storage ................................................... 66

Figure 5-2: Power Distribution with Energy Storage .......................................................... 69

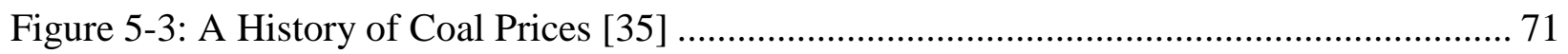

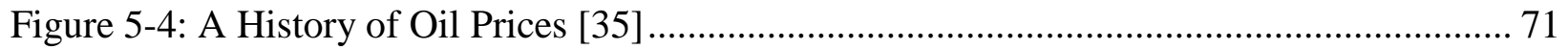

Figure 5-5: A History of Gas Prices [35] ..................................................................... 71 
NOMENCLATURE

\begin{tabular}{|c|c|}
\hline Acronym or Symbol & Description \\
\hline$\nabla$ & gradient \\
\hline$\lambda$ & incremental cost rate \\
\hline BASE & beta-alumina solid electrolyte \\
\hline CAES & compressed air energy storage \\
\hline $\mathrm{Cmr}$ & commercial \\
\hline Dis & discharge \\
\hline$F_{\text {coal }}$ & fuel cost for the coal fired generator \\
\hline$F_{\text {gas }}$ & fuel cost for the gas turbine generator \\
\hline$F_{i}$ & fuel cost for the ith thermal generator \\
\hline$F_{\text {oil }}$ & fuel cost for the oil fired generator \\
\hline$H_{\text {coal }}$ & heat input for the coal fired generator \\
\hline$H_{\text {gas }}$ & heat input for the gas turbine generator \\
\hline$H_{i}$ & heat input for the ith thermal generator \\
\hline$H_{o i l}$ & heat input for the oil fired generator \\
\hline$k$ & discrete time in hours \\
\hline $\mathrm{L} / \mathrm{A}$ & lead-acid \\
\hline Lgt & lighting \\
\hline $\mathrm{NaS}$ & sodium (natrium) sulfur \\
\hline $\mathrm{Na}_{2} \mathrm{~S}_{\mathrm{x}}$ & sodium polyssulfide \\
\hline NGK & Nihon Gaishi Kaisha \\
\hline $\mathrm{PbO}_{2}$ & lead oxide \\
\hline $\mathrm{PbSO}_{4}$ & lead sulfate \\
\hline
\end{tabular}




\begin{tabular}{c|c}
\hline Acronym or Symbol & Description \\
\hline$P_{\text {coal }}$ & output power for the coal fired generator \\
$P_{\text {dis }}$ & storage discharging power \\
$P_{\text {gas }}$ & output power for the gas turbine generator \\
$P_{i}$ & output power for the ith thermal generator \\
$P_{\text {oil }}$ & output power for the oil fired generator \\
$P_{\text {load }}$ & total system power demand \\
$P_{\text {storage }}$ & power output from energy storage \\
ROI & return on investment \\
Rsi & residential \\
SMES & continuous time \\
$t$ & superconducting magnetic energy storage \\
T\&D & Tokyo Electric Power Company \\
TEPC & zinc-bromine \\
VRB & vanadium redox battery \\
\hline
\end{tabular}




\section{ACKNOWLEDGMENTS}

First I would like to thank my son Noah who is my ultimate source of motivation. He has provided my life with so much clarity and purpose since his birth which coincidentally was about the time that I started this thesis work. I would also like to thank my girlfriend Amanda Buerkle for being such a wonderful mother. Graduate school can be tough not only on the student but on the students family as well. Amanda is the backbone to our family and whenever I am feeling overwhelmed, she is always there to offer her support. I would like to thank my parents for being there for me from day one. My parents have never pushed me to do anything that I didn’t want to do and have always had words of encouragement with every path that I have chosen. There were times as an undergraduate student when I barely had the financial means to make it and I want to offer a special thank you to them for the financial assistance that they had provided me. I want to thank my siblings Justin, Breanne and Julian as well as my brother in law Jeremy for always being there when I needed someone to talk to and for being my best friends in the world.

I want to thank Dr. Reed and the Electrical and Computer Engineering Department for having faith in me to be a productive graduate student. It would be very hard to attend graduate school while working full time and I probably would not be here if it hadn't been for them. Working for Dr. Reed as a research assistant and for the ECE department as a teaching assistant 
gives me the ability to focus all of my efforts on school and gives me the best possible opportunity for success.

I would like to thank everyone who served on my committee; Dr. Kusic for being there to guide me and provide his knowledge and expertise; Dr. Mao for pushing me to be a better student and maximizing my potential; Dr. Mickle for helping me formulate a thesis worthy problem and inspiring me to think creatively. I would also like to thank some of the other professors that have inspired me in my academic career. These professors listed in no particular order are Dr. Joel Falk, Dr. Steven Jacobs, Dr. William Stanchina, Dr. Minhee Yun, Ms. Alexandra Tauson, Dr. Theodore Worek, Dr. William Troy, Dr. Stuart Hastings, Dr. Anna Vainchtein, Mr. Ryan O’Grady and Mr. Justin Dunmyer.

I would like to thank my graduate student peers who help a tremendous amount. These are the people that can help me academically if I have a question but can also just be friends. We have a lot of fun together and they inspire me to work harder as well. Listed in no particular order they are Matt Korytowski, Brandon Grainger, Robert O’Connor, Mircea Lupu, Adam Sparacino, Emmanuel Taylor, Azime Can, Hussain Bassai, Vikram Thiruneermalai Gomatam, Jean-Marc Coulomb, Benoit Decourreges, Adam West and Nick Franconi.

I would also like Ludwig Van Beethoven, Johann Sebastian Bach and the Wu-Tang Clan for silencing out some of life's audible distractions. I wrote the vast majority of this thesis while listening to the amazing music created by them and it served as inspiration the whole way through.

Last but not least I would like to thank two of my best friends who are always there for anything that I need in life. This special thank you goes to David Beeson and Ji-Hwan (Rick) Kwon. 


\subsection{INTRODUCTION}

The last couple of decades have been a great time of change for the power industry. There are many new and exciting areas in the field of electric power generation and distribution that may be a potential solution to improvement of the grid one day. When looking for a solution to powering the grid one has to consider more than just the factor of economics but also feasibility and environmental issues as well.

Renewable or green solutions to powering the grid are becoming ever more present as pressure is being put on industry from the government. One promising form of green energy is the use of large grid scaled energy storage. Energy storage is promising due to the multitude of applications that it can be used for.

Renewable generation sources such as wind power and solar power are generated by stochastic environmental processes such as the sun shining or the wind blowing and must be used instantaneously. Power that is generated by these energy sources can be used in the most effective manner by integrating energy storage due to the fact that power generated by these stochastic processes sometimes cannot be used immediately and is best stored until it is needed.

Energy storage can also be used for several maintenance purposes. Today’s infrastructure is clearly aging and in need of modernization. One of the biggest problems that impede the process of repairing and updating the grid is the grid's need to be energized at all times, especially when dealing with sensitive loads. Energy storage can be used, rather than 
some of the more expensive and time consuming methods which require a certain part of the grid to be de-energized.

The applications of energy storage which appears to yield the largest economic gain are the applications of peak shaving and load leveling. Peak shaving has been used in the past both for the protection of electric systems and for financial gain. As the price of large grid scaled energy storage decreases the overall amount of financial gain increases.

This thesis explores the economics and feasibility of load leveling with large grid scaled energy storage systems. There are several different types of energy storage units that can be used for load leveling but in this study only large NaS battery farms and pumped storage facilities will be explored and compared. The charging and discharging rates are modeled so that the power that is allocated is accurate to real world application.

\subsection{PROBLEM STATEMENT AND MOTIVATION}

Peak shaving has been proven useful for grid level application using storage devices rated at less than $10 \mathrm{MW}$, which both protect equipment and reduce the cost of equipment due to lowered peaks [1]. This study addresses energy storage with a system power rating of $600 \mathrm{MW}$ used for the application of load leveling and the effect it will have on the system load.

It is known that gas turbine generators are quite expensive to use but are needed due to the fact they can respond to changes in the system load much faster than fossil fuel operated thermal generation units [2]. However, if very large energy storage units could be used flatten the system load enough, the gas turbine generators would not be needed to supply the system load, potentially reducing the cost of generation. 
A completely flat load profile would reduce the overall cost of generation due to the fact that all thermal generators could be operated at the same output power rating at all times. Ideally it would be very beneficial to use energy storage to achieve a completely flat load profile, however due to the non-constant discharging rates of energy storage units it would take a very large quantity of energy storage units to achieve this, and in turn, it would be more costly than anything. With a reasonable amount of energy storage units, the best case that can be achieved is much flatter than the original load profile but not quite perfectly flat.

The best type of energy storage for the application of load leveling must also be investigated in order to determine its feasibility and the economic benefit that they yield. There are certain benefits that some forms of storage may have that other forms do not. This study also investigates the different forms of energy storage in order to find the form that is most applicable for load leveling.

Energy storage that is modeled according to its charging and discharging profiles needs to be allocated effectively to observe its usefulness for load leveling. In this study optimization methods are used in conjunction with the charging and discharging profiles of the energy storage units to allocate the stored energy in the most effective way possible.

As of now grid level energy storage is not being used according to the methods discussed in this study. However, with growing concerns about the earth's environment comes the need for mankind the further itself from the use of fossil fuels. Therefore, either if large grid level energy storage is or is not the most economical solution for the allocation of electric power it still will be a promising green solution and should be investigate either way. 


\subsection{THESIS ORGANIZATION}

Chapter 2.0 of this thesis covers grid level energy storage as it is applied to load leveling and peak shaving. Section 2.1 gives a treatment of both peak shaving and load leveling by explaining the procedure for both and covering the differences between them. Five different types of energy storage that can be used for grid level applications are covered in Section 2.2. In this section the operation, the advantages and the disadvantages of each type of storage are thoroughly discussed. The third section of chapter two briefly covers distributed energy storage systems and their applications to the electrical grid.

Chapter 3.0 of this thesis covers the optimization methods that are used in this study. Section 3.1 gives a thorough layout of the economic dispatch problem. The economic dispatch problem uses a system of quadratic fuel cost curves which are a function of output power and optimizes their operating point by means of Lagrange multipliers. The constraint equation in both the case where there are transmission losses and where there are no transmission losses is covered. Section 3.2 covers the dynamic programming method of and how it is applied to the allocation of energy storage. Thermal generation units have constraints on their maximum/minimum change per time step, maximum/minimum up and down times and their cold start times. The commitment of these units based on their constraints is referred to as the unit commitment problem and is covered in the third section of Chapter 3.0 .

The objective of this study was to do an economic analysis of the energy storage units being used to replace gas turbine generators. Chapter 4.0 sets up both the case in which there are gas turbine generators used and the case in which energy storage is used to replace them.

Section 4.1 models the fuel cost curves of the thermal generators used in this study. Section 4.2 
covers the unit commitment problem specific to this study. Section 4.3 models the system load that is used for this problem. The energy storage that is used in this study had to be modeled according to charging and discharging rates and allocated to level the load. The methods that were used for this modeling and allocation are discussed in Section 4.4 and in Section 4.5. The sixth section of Chapter 4.0 sets up the economic dispatch for both the case with energy storage and without energy storage based on the unit commitment constraints.

Chapter 5.0 of this study provides the analysis that was carried and the results. The results of the economic dispatch for the case in which there is no energy storage and for the case in which there is energy storage are given in Section 5.1 and Section 5.2 respectively. Section 5.3 provides a cost analysis which includes the economic gain due to the use of energy storage versus the total cost of the storage.

Chapter 6.0 and Chapter 7.0 give a conclusion of the work that was performed in this study as well as future work that is required to make this study more robust. 


\subsection{GRID LEVEL ENERGY STORAGE}

In today’s electric power infrastructure there are many applications and uses for grid level energy storage such as; the allocation of stored renewables, peak shaving, load leveling and grid support for maintenance. Installations of large grid level energy storage systems are becoming more common. $8 \mathrm{MW}$ of a total $20 \mathrm{MW}$ battery energy storage system was recently installed in Johnson City, NY just this year [42]. The use of grid level energy storage is a highly sought after aspect of power systems technology because of the economic return it could potentially produce. This chapter discusses the difference in load leveling and peak shaving through the means of large grid level energy storage, five different types energy storage that can be used at the grid level and distributed energy storage systems.

\subsection{PEAK SHAVING VS. LOAD LEVELING}

Peak shaving and load leveling are both processes which store electrical energy when the electrical load is low and discharge the stored energy when the electrical load is high. In the case for peak shaving the energy is stored during a time in which the system load is low and discharged to remove only the peaks of the load. For load leveling the same process takes place except the goal is to flatten the load rather than just remove the peak. For nearly every load 
profile the system demand is low during the early morning hours and is high in the midday through evening hours, especially during rush hour. Therefore energy storage will be charged during the early morning hours and discharged during the midday and early evening hours.

\subsubsection{Peak Shaving}

Figure 2-1 illustrates the use of energy storage for the application of peak shaving. During the early morning hours from about 0000 to 0800 the load is slightly raised while the storage is charging. The storage is then discharged when the so that the load's peaks are removed.

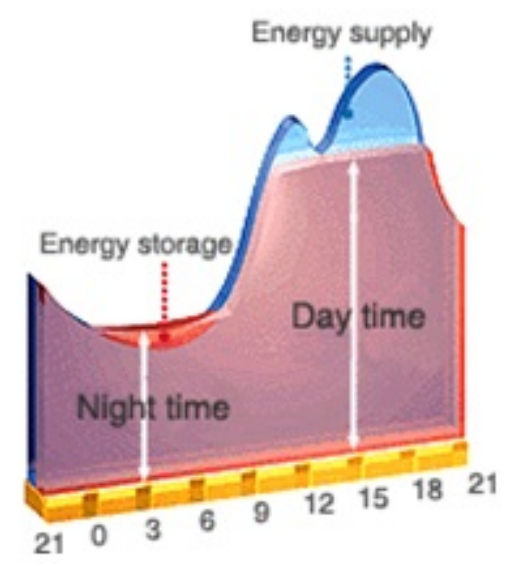

Figure 2-1: Peak Shaving Diagram [3]

There are many applications which peak shaving can be used for, which range from equipment protection to economic gain. The application in which peak shaving is being used for determines the size and the type of the storage that is needed. 


\subsubsection{Load Leveling}

This study is aimed at the application of load leveling. The goal of load leveling is to make the load as flat as possible. This technique is very promising when it comes to the economic benefits that it can yield. Figure 2-2 illustrates the use the load leveling application.

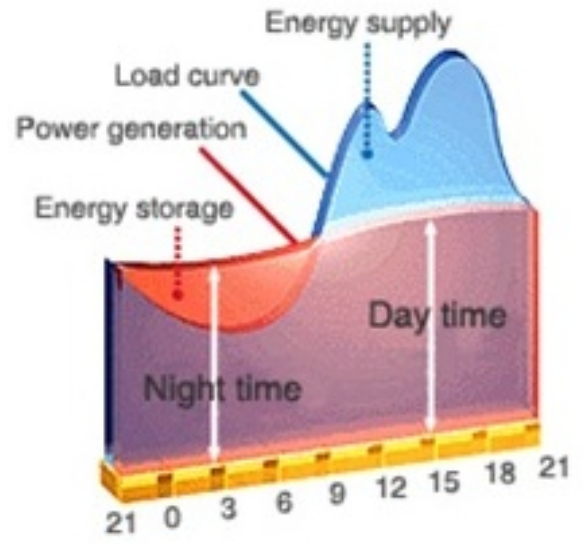

Figure 2-2: Load Leveling Diagram [3]

It should be noted that for the load leveling application there is much more energy storage required. The charging of the energy storage raises the load where the load "dips” during the early hours of the morning. For load leveling the load should be raised or lowered to the systems average load value. It can be seen from Figure 2-2 that the load with the addition energy storage remains about constant from hour 2100 to hour 0900. This is the time in which the storage device is charging and hence the load is raised due to the power demand that the storage devices require. The stored energy is then discharged during the midday and early evening hours in an attempt to maintain a flat load profile. It can also be seen from Figure 2-2 that the load has two peaks. These two peaks present the challenge of deciding when to discharge the storage devices. One solution to this problem is to discharge half of the storage device during the first peak and then discharge the other half of the storage device during the second peak. However, 
unless both peaks are exactly equal in magnitude, which is highly unlikely, the load will still remain uneven after both discharges. A solution to this problem is to use multiple storage devices and allocate a greater amount of stored energy for the larger peak and a lesser amount for the smaller peak.

\subsection{TYPES OF ENERGY STORAGE}

As was discussed in this chapter, the application that energy storage is being used for determines the size and type of storage. This section discusses the different types of storage and their applicability for load leveling.

Figure 2-3 illustrates the different types of energy storage that can be used as they range in system power rating and discharge time at rated power.

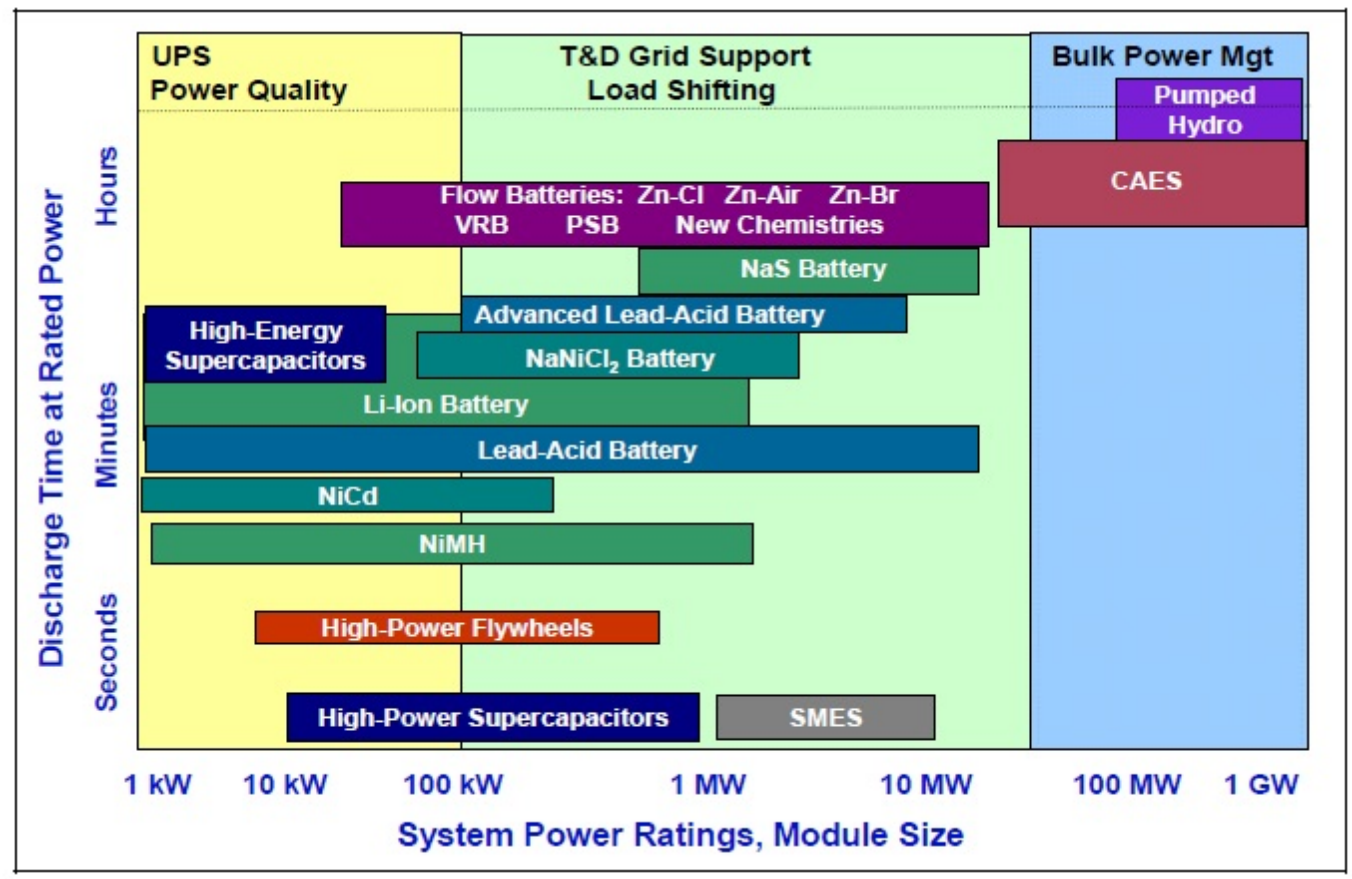

Figure 2-3: Positioning of Energy Storage Technologies [6] 
For this study the interest in energy storage is used for the application of load leveling which requires a storage device with a very large system power rating and only those types of storage devices will be discussed. It should be noted that there are types of energy storage which can have a very large system power rating but can’t discharge at rated power for a long enough time. A good example of this is a $26 \mathrm{MW}$ NiCd battery installation that was installed in Alaska by the Golden Valley Electric Association [41]. While this battery is at a power rating of 26 MW, it can only discharge for 15 minutes which is not applicable to load leveling.

\subsubsection{Sodium Sulfur Batteries}

Sodium sulfur $(\mathrm{NaS})$ batteries are a very promising form of large grid scaled energy storage. These batteries have been in construction since the 1990s in Japanese businesses and as of the year 2007 could power the equivalent of 155,000 homes [4].

The NaS cell was developed jointly by the Japanese companies NGK and the Tokyo Electric Power Company (TEPC) [3]. NaS has proven that it can be used as a large grid scaled energy storage system when it was used to construct the world's largest energy storage system at Futamata in Aomori Prefecture in May 2008 which had a power rating of 34 MW. This energy storage system was constructed with the primary goal of supporting a 51 MW wind farm [5]. NGK has also constructed a 1.2 MW battery that was shipped to the United States for DESS use [1]. 


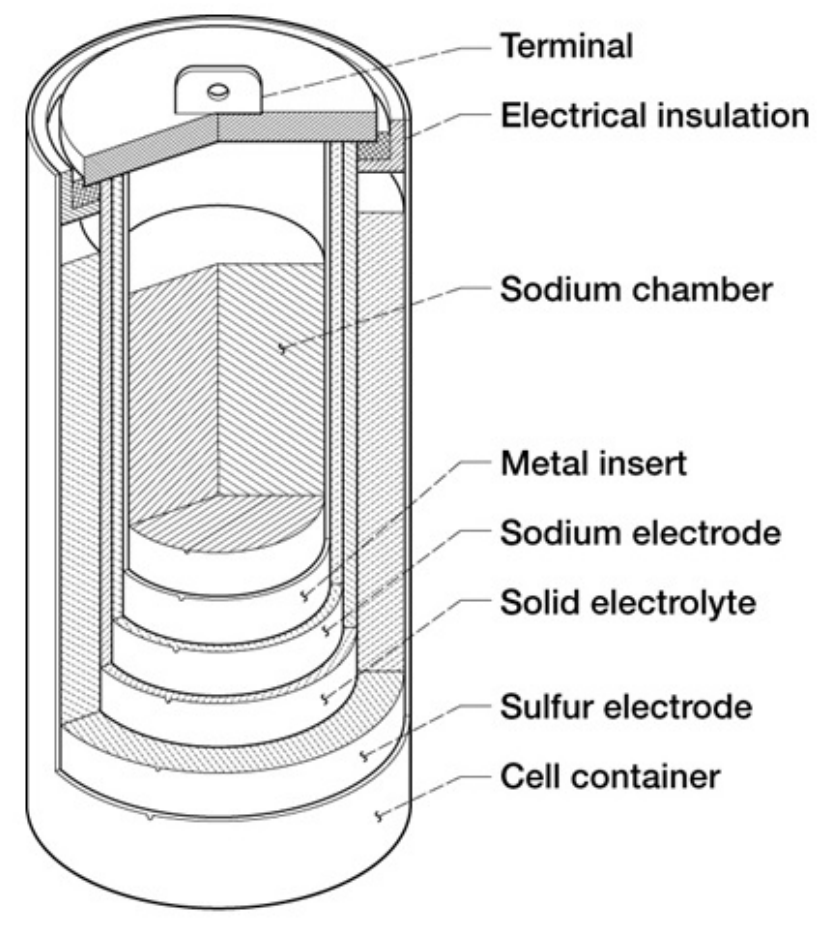

Figure 2-4: NaS Battery Schematic [19]

Figure 2-4 illustrates the schematic diagram of a NaS battery. The core of the battery contains pure molten sodium which is encased by a metal insert. Outside of the sodium chamber is a negative sodium electrode and a positive sulfur electrode which is separated by a betaalumina solid electrolyte (BASE) membrane. During the discharging process the sodium flows between the BASE membrane and a safety tube which controls the amount of sodium and sulfur that can combine in the case in which the BASE fails. This sodium produces $\mathrm{Na}^{+}$ions through the process of oxidation at the sodium/BASE interface. These ions then travel through the BASE membrane and combine with sulfur that is being reduced in the positive electrode to form sodium polysulfide $\left(\mathrm{Na}_{2} \mathrm{~S}_{\mathrm{x}}\right)$. The charging process is the same chemical process only reversed $[7,8]$.

There are many advantages to using NaS batteries for large grid scaled applications. As far as batteries go NaS ranks at the very top along with a couple chemical compositions in terms of system power capacity. It can be seen from Figure 2-3 that NaS batteries along with flow 
batteries and lead acid batteries can discharge at a power rating of up to $10 \mathrm{MW}$ for hours. NaS batteries are also advantageous for the length of their cycle life. NaS batteries have a cycle life of up to 2500 cycles for $100 \%$ depth of discharge and up to 5000 cycles for $90 \%$ depth of discharge [1]. These batteries while operating daily can last as long as 15 years giving them a clear advantage over other large scaled batteries such as lead acid. Lastly, NaS batteries are advantageous due to their high energy density and charging and discharging efficiency of up to 92\% [9]. Using a NaS battery for ac applications both for charging and discharging lead to an 80\% battery efficiency [3].

The disadvantages of $\mathrm{NaS}$ batteries are that they are limited to being used only for grid scale applications due to their operating temperatures which can be as high as $350^{\circ}$ Celsius. This study is only focused on grid scaled applications so this is not problematic. Sodium sulfur batteries, like all batteries, are also expensive.

\subsubsection{Lead-Acid Batteries}

Lead-Acid (L/A) batteries were the first rechargeable batteries to be invented. They were invented by the French physicist Gaston Planté in 1859. Today L/A batteries range in application from small applications such as motor vehicle starting engines and household appliances all the way up to grid level applications on the megawatt scale $[3,10]$.

L/A batteries consist of two lead plates which are submerged in a pool of liquid electrolyte made of water and sulfuric acid creating an anode and a cathode. A chemical reaction takes place in the discharging process which both the anode and the cathode become lead sulfate

$\left(\mathrm{PbSO}_{4}\right)$. This generates the flow of electrons from the positive terminal to the negative 
terminal. During the recharging process the sulfates decompose so that the cathode is composed of lead oxide $\left(\mathrm{PbO}_{2}\right)$ and the anode is composed of elemental lead [11,12].

L/A batteries have the advantage of being the most technologically mature out of all of the rechargeable battery chemical compositions. Therefore, they are useful in the sense that not a lot of research has to go into them in order to put them into applications. However they have many disadvantages that make other chemical compositions better choices for grid scaled applications.

One of the biggest disadvantages to L/A batteries is their limited cycle life. For grid applications it is highly desirable to have a storage device that can last for a very long time in order to maximize the economic gain that it produces. The world's supply of lead is also limited. At the pace in which lead is being mined and used today the supply of lead will be exhausted in the year 2049 [13]. Lead-Acid batteries are also very heavy and bulky making them hard to transport and a poor choice for grid scaled applications which require transportation of the battery.

Although lead-acid batteries are probably not the ideal choice of battery for large grid scaled applications there still have been a couple large installations for the use of T\&D applications. There is a $1 \mathrm{MW} / 1.5 \mathrm{MWh}$ installation that is operating in Alaska and there have been up to $20 \mathrm{MW}$ installations deployed around the world.

\subsubsection{Flow Batteries}

Flow batteries, also known as redox batteries, are electrochemical devices which can store electrical energy with the use of electrolyte tanks $[3,14]$. Flow batteries work by using electrodes as an electron transfer surface. Energy is stored in the form of ions in two electrolyte 
tanks. One of the tanks is used for positive electrode reaction and the other is used for negative electrode reaction. The electrolytes are pumped through and electrolytic circuit which contains a reaction cell which separates the two electrolytes by means of an ion-exchange membrane in order to discharge the stored energy in the form of electricity [15]. This process is illustrated in Figure 2-5.

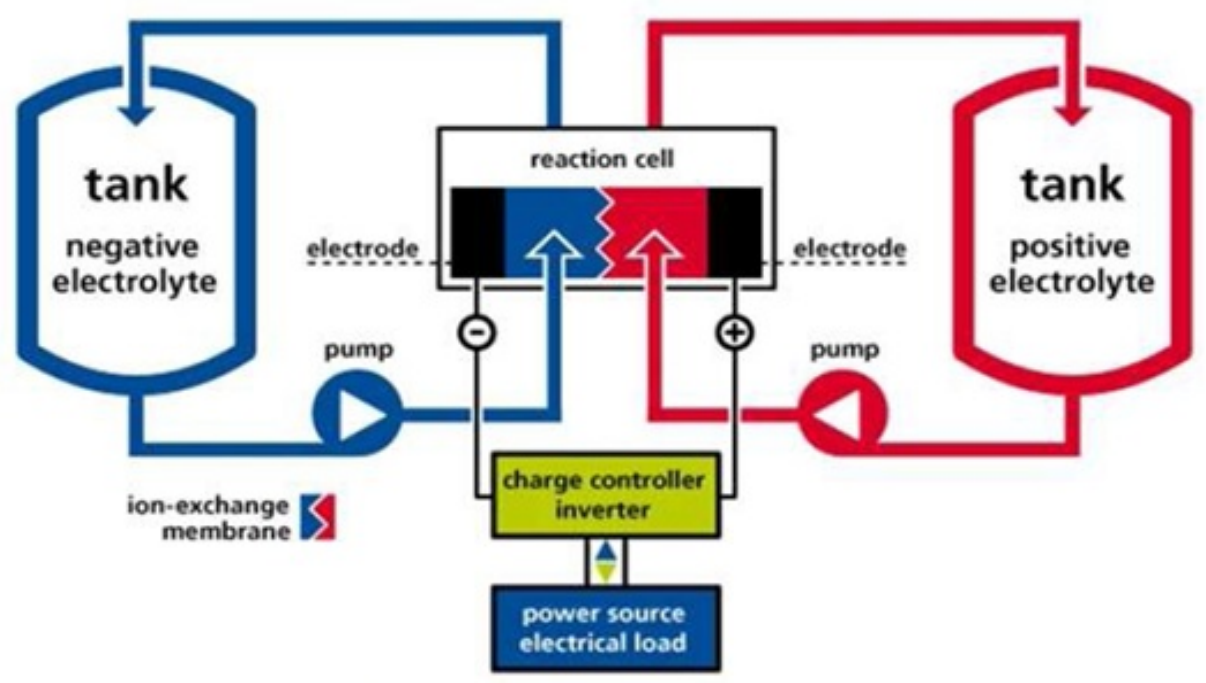

Figure 2-5: Flow Battery [11]

Flow batteries do have the disadvantage of their technological maturity. In comparison to other batteries such as NaS and L/A, flow batteries are fairly new and in the early stages of their development. The vanadium redox battery (VRB) is the most technologically mature out of all of the flow type batteries. The first successful operation of an all vanadium redox battery demonstrated in the early 1980s at the University of South Whales [16]. Flow batteries such as zinc-bromine $(\mathrm{ZnBr})$ are in the early demonstration and deployment stages where as other flow batteries such as zinc-air (Z/air) are still in the R\&D stage. 


\subsubsection{Pumped Storage}

Pumped storage can store massive amounts of energy and have a system power rating of several hundreds of megawatts up to gigawatts. The world's largest pumped storage is the Bath County Pumped Storage Station which has a system power rating of approximately 2.7 GW [17]. Pumped storage stations are currently the most efficient way of storing mass amounts of energy [8].

Pumped storage works on the principal that electricity is used to pump water up a mountain and stores until the energy is needed i.e. when the system demand is high. The water that is stored on top of the mountain is released down the mountain and through a hydro-turbine generator which creates electricity. Figure 2-6 shows a diagram of the Raccoon Mountain Pumped Storage Plant which has a system capacity of 1.6 GW [18].

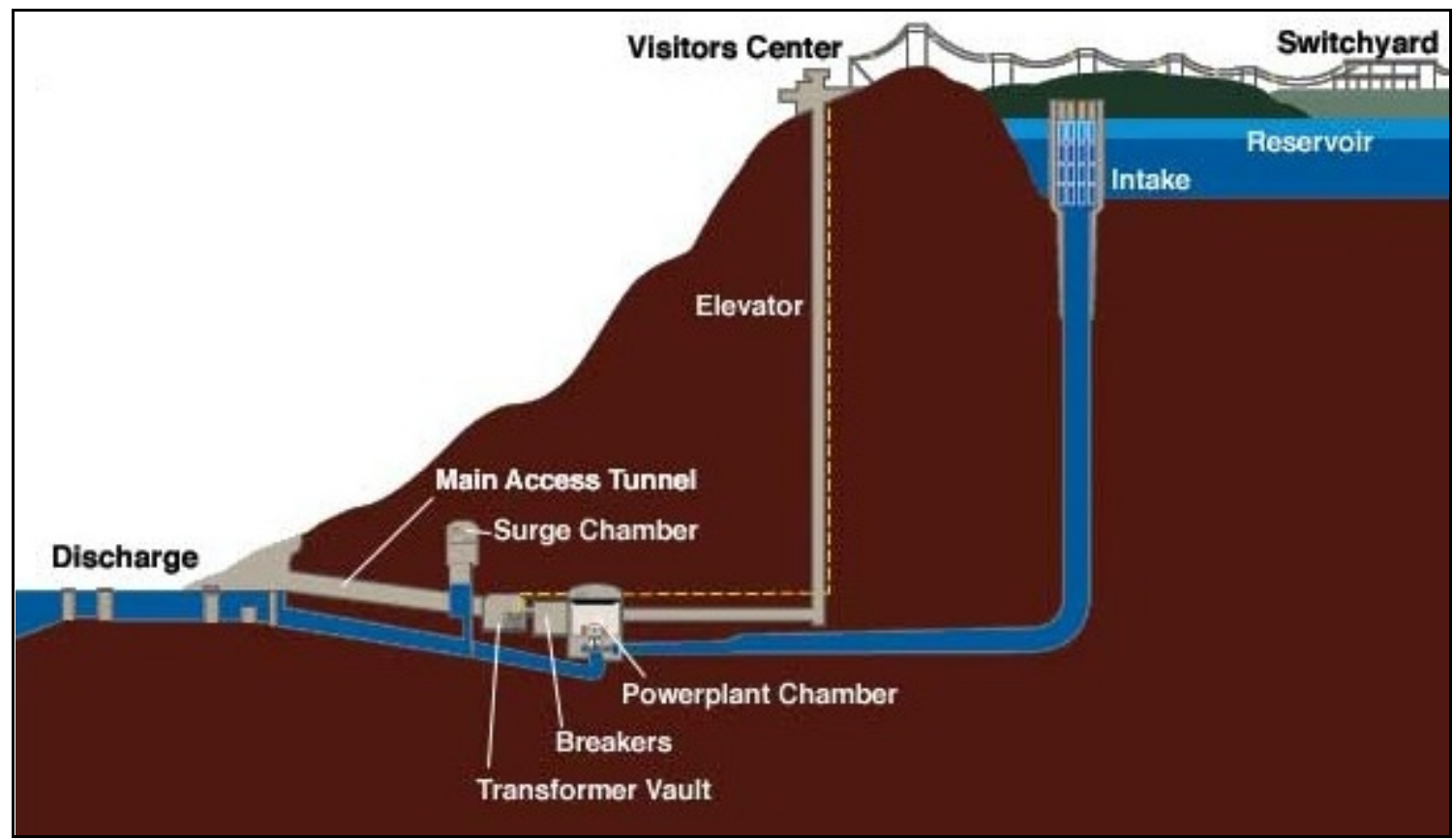

Figure 2-6: Raccoon Mountain Pumped-Storage Plants [18] 
Pumped storage is highly advantageous for applications such as load leveling which require a very large system power rating, due to their capacity. For a pumped storage plant such as the one at Raccoon Mountain it would take hundreds of the largest batteries available to equal the system power rating. Pumped storage is also very efficient and cost effective as a means of mass energy storage.

For as many advantages that pumped storage has, it also has a large disadvantage. The location at which pumped storage can be used is completely dictated by its geography and is therefore its biggest disadvantage. In order to have a pumped storage plant there must be a lower reservoir that can store a large amount of water. A lake is an ideal lower reservoir because it already has all of the water that will be needed for storage. There must be an upper reservoir that is used to store the water pumped from the lower reservoir. The horizontal distance between the upper and lower reservoir should be short. This minimizes hydraulic losses and increases the velocity of the downward flowing water, increasing response time. The plant must be built on and around solid rock that can support it and somewhere with little environmental problems. The plant should also be built close to existing generation sources so the amount of transmission losses is kept at a minimum [20]. All of the geographical requirements for a pumped storage plant limit the possible locations for construction. The discharge time for pumped storage can range anywhere from seconds to several hours and can also be a disadvantage [21].

\subsubsection{Compressed Air Energy Storage}

Compressed air energy storage (CAES) is a form of energy storage which compresses air and then stores it for a later use. CAES technology has been around for over 40 years. Similar to 
pumped storage in storage capacity, CAES has the potential capacity for a system power rating in the hundreds of megawatt level [3,21].

Air in a CAES plant is compressed, cooled and stored with the use of electricity at a high pressure within the earth or inside a tank. This air acts as stored energy until it is later needed. It is then heated, expanded and fed through a turbine-generator to generate electricity. There are three generations of CAES. The first generation CAES system uses natural gas which is burnt with air and sent through a turbine generator. The second generation CAES systems use the same process as the first except the system is flexible to meet smart grid. Second generation CAES plants have from $60-70 \%$ green energy [22]. Third generation CAES plants do not use the gas turbine and likewise do not use any natural gas. The benefit of third generation CAES plants is that there are zero carbon emissions. The only generation that is in commercial use is the first generation. Generations two and three are still in the developmental phase. Figure 2-7 is the schematic diagram for a first or second generation CAES plant. 


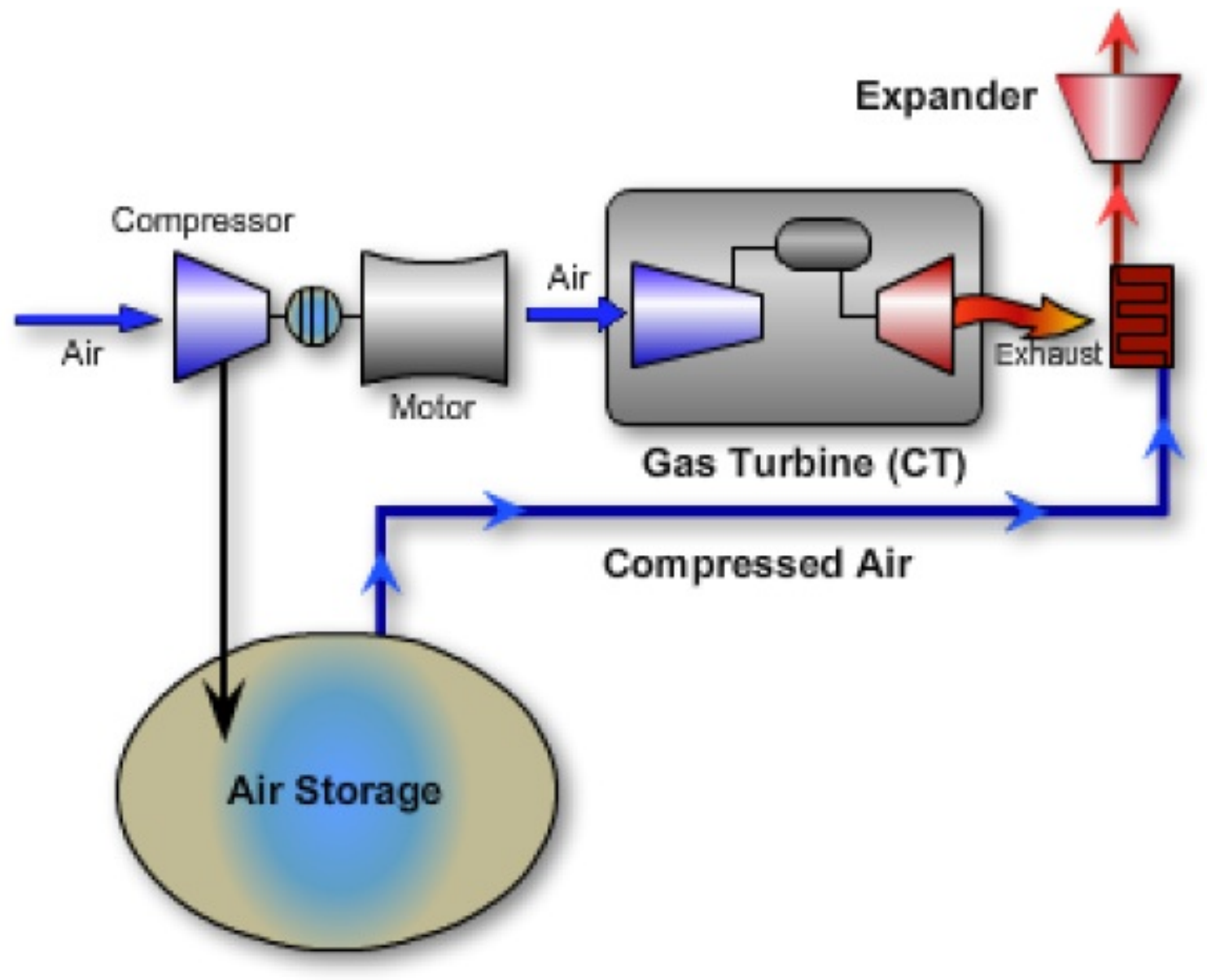

Figure 2-7: CAES Plant Schematic [22]

Although the energy storage capacity for CAES plants is desirable due to the fact that it can store massive amounts of energy. At this point that might be the only possible advantage that CAES has.

CAES is disadvantageous for several reasons. First, CAES has the slowest response time out of all of the large scale storage devices. The response time for a CAES plant can range anywhere from a couple hours to over one day $[3,21,23]$. For applications such as load leveling and peak shaving with a very consistent load profile this will not pose that great of a problem but for all other storage applications it will. Second, CAES with the exception of the third generation plants produces emissions. One of the greatest benefits to using storage such as $\mathrm{NaS}$ 
batteries, flow batteries and pumped storage is that there are little to no emissions in the charging and discharging processes. Lastly, CAES with the exception of third generation plants is not as efficient as other grid scaled storage devices

\subsection{DISTRIBUTED ENERGY STORAGE SYSTEMS}

Distributed energy storage systems (DESS) are energy storage systems of up to a $10 \mathrm{MW}$ capacity which are installed on the utility side of the grid and can serve office facilities, residential complexes and commercial facilities [1,3]. Applications of DESS include grid support for maintenance, the development of new infrastructure and peak shaving. DESS can be movable which make them ideal for maintenance and the installation of new power systems equipment. The construction of new transmission lines and substations, and the installation of new transformers can take several years to complete because it is dangerous to work on energized equipment. A solution to this problem is to de-energize the equipment and then perform the required work but most equipment can’t be de-energized especially when dealing with sensitive loads. However with movable DESS, electrical systems can be disconnected from the original power source at the area that is in need of work and re-energized with the DESS. When the required work is complete the DESS can be moved to another section of the grid that needs work. This technique can prove to be very useful for the development of the future

electric power grid. Figure 2-8 illustrates the use of movable DESS for the use of system maintenance. 


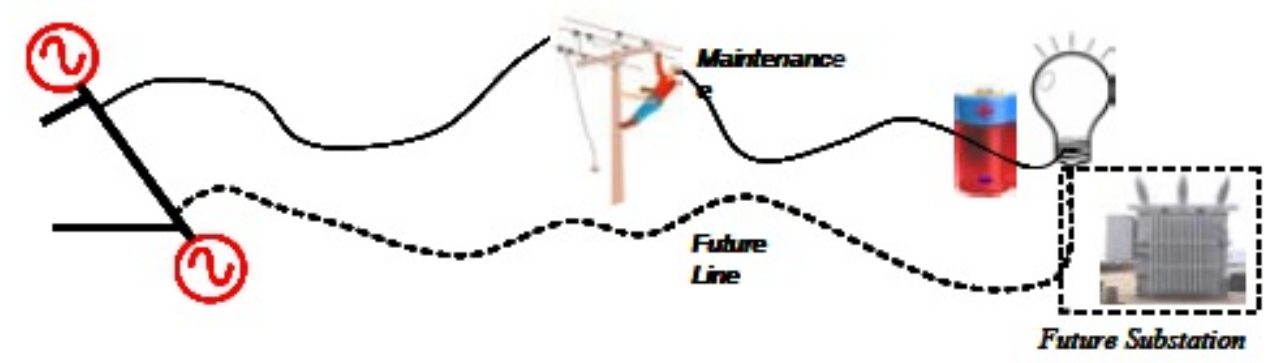

Figure 2-8: DESS Used for Grid Maintenance [1]

When all of the maintenance or work that needs to be performed is completed the DESS can be moved closer to the substation to provide the grid with load support.

DESS systems are useful for the applications that require a power rating of up to $10 \mathrm{MW}$. However, for the application of load leveling much larger storage devices will be required due to the fact that $10 \mathrm{MW}$ and under is only a very small fraction of the grids power demand. Storage devices on the scale of hundreds of megawatts or greater, such as NaS batteries in parallel, pumped storage, flow batteries and CAES would simply be too large to move from one are of the grid to the other. 


\subsection{OPTIMIZATION OF THERMAL GENERATION UNITS AND ENERGY STORAGE}

Optimization methods are used to find the most economical solution to allocate power generated by thermal generation units. This chapter focuses on the optimization of thermal generation units that have to meet a system load with the integration of grid level energy storage. The most economical solution to dispatching the power generated by the thermal generators is found by using the economic dispatch method of optimization. The energy storage is dispatched by using a highly predictable system load and then allocating the stored energy with the dynamic programming method of optimization. These techniques are discussed in detail in this chapter.

\subsection{THE ECONOMIC DISPATCH PROBLEM}

The economic dispatch problem is stated as an optimization method which uses Lagrange multipliers along with a function for each thermal generator called the cost rate to mathematically find the optimal solution. Each thermal generator has its own set of constraints that must be followed when finding the optimal solution. A daily load must be broken up into incremental time steps, each having its own economic dispatch solution. 


\subsubsection{Lagrange Multipliers and the Method of Optimization}

A system of equations with unknown variables can be solved for some optimal value using techniques from calculus. It is known that where a function's first derivative is equal to zero is where that function has either a minimum or a maximum. In the case of economic dispatch we are dealing with a cost function and optimizing a cost function is obviously solving for its minimum value. Economic dispatch uses this same theory to find the minimum cost of several generators each with its own cost function. The method of Lagrange multipliers must be introduced to find the minimum cost value for the system.

Consider a function $f\left(x_{1}, x_{2}, \ldots, x_{n}\right)$. This function will be called the objective function i.e. the function that is to be minimized. Then consider also a function $g\left(x_{1}, x_{2}, \ldots, x_{n}\right)$. This function will be called the constraint function i.e. the conditions that have to be met while minimizing the objective function. In order to find the minimum solution or the optimum point for the objective function, the gradient of $f(\nabla f)$ must be normal to $g$. The gradient of $f$ is defined as a vector field which points in the direction of the greatest rate of increase of the scalar field $f$ [3.1] and is represented by (3.1).

$$
\nabla f\left(x_{1}, x_{2}, \ldots, x_{n}\right)=\frac{\partial f\left(x_{1}, x_{2}, \ldots, x_{n}\right)}{\partial x_{1}} \mathbf{e}_{1}+\frac{\partial f\left(x_{1}, x_{2}, \ldots, x_{n}\right)}{\partial x_{2}} \mathbf{e}_{2}+\ldots+\frac{\partial f\left(x_{1}, x_{2}, \ldots, x_{n}\right)}{\partial x_{n}} \mathbf{e}_{n}
$$

Where $\mathbf{e}_{\mathbf{1}}, \mathbf{e}_{2}, \ldots, \mathbf{e}_{\mathbf{n}}$ are linearly independent vectors which form a subspace in $\Re^{n}$. It can be guaranteed that $\nabla f$ is normal to $g$ by requiring that $\nabla f$ and $\nabla g$ are linearly independent of each other. It can be ensured that these vectors are linearly independent of one another by using a Lagrange multiplier as used in (3.2). 


$$
\nabla f+\lambda \nabla g=0
$$

For some $\lambda$. From (3.2) the Lagrangian can be derived which is described by (3.3).

$$
\Lambda\left(x_{1}, x_{2}, \ldots, x_{n}, \lambda\right)=f\left(x_{1}, x_{2}, \ldots, x_{n}\right)+\lambda g\left(x_{1}, x_{2}, \ldots, x_{n}\right)
$$

From (3.3) the optimal solution can be found. The optimal solution is described as the set of equations in (3.4)

$$
\begin{gathered}
\frac{\partial \Lambda}{\partial x_{1}}=0 \\
\frac{\partial \Lambda}{\partial x_{2}}=0 \\
\vdots \\
\frac{\partial \Lambda}{\partial x_{n}}=0 \\
\frac{\partial \Lambda}{\partial \lambda}=0
\end{gathered}
$$

The optimal solution by means of using Lagrange multipliers can be best seen when the objective function and the constraint function are functions of two variables. In this case the Lagrangian becomes (3.5)

$$
\Lambda(x, y, \lambda)=f(x, y)+\lambda g(x, y)
$$

This can be shown graphically as shown in Figure 3-1. Note that the point where $g(x, y)=c$ crosses $f(x, y)=d_{1}$ is the optimal solution for the objective function equal to $d_{1}$ and the point where $g(x, y)=c$ crosses $f(x, y)=d_{2}$ is the optimal solution for the objective function equal to $d_{2}$. 


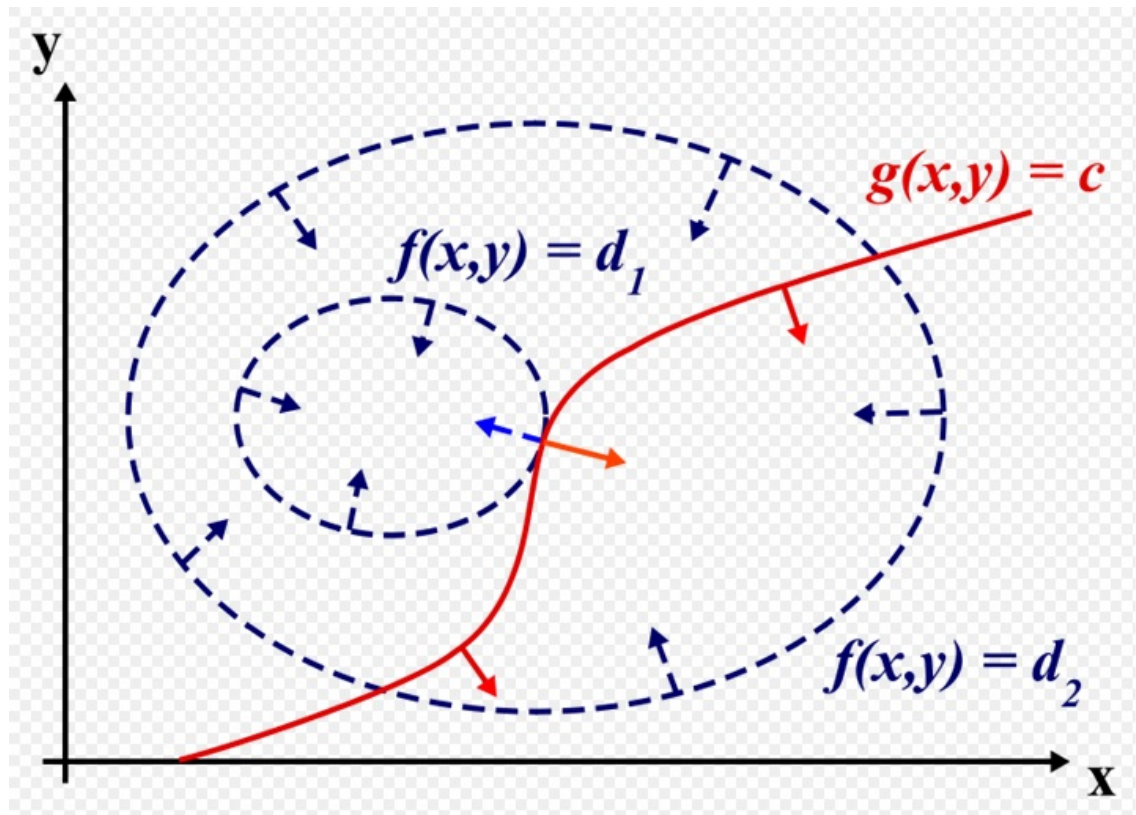

Figure 3-1: Graphical representation of optimal solution using the Lagrange multipliers [24]

\subsubsection{Solution to Thermal Generating Units Using Lagrange Multipliers}

The economic dispatch problem can be solved using the theory of Lagrange multipliers described in the preceding subsection. The economic dispatch problem is configured such that there are $n$ generators which all have a cost function of quadratic nature. These generators feed a single point bus which in turn feeds the system load [25]. The objective is used to find the operating point for each of the $n$ generators which yield the optimal solution. In the case of economic dispatch, the solution minimizes the operating cost of the sum of all $n$ generators. This configuration can be seen in the form of a one line diagram represented in Figure 3-2 [25]. 


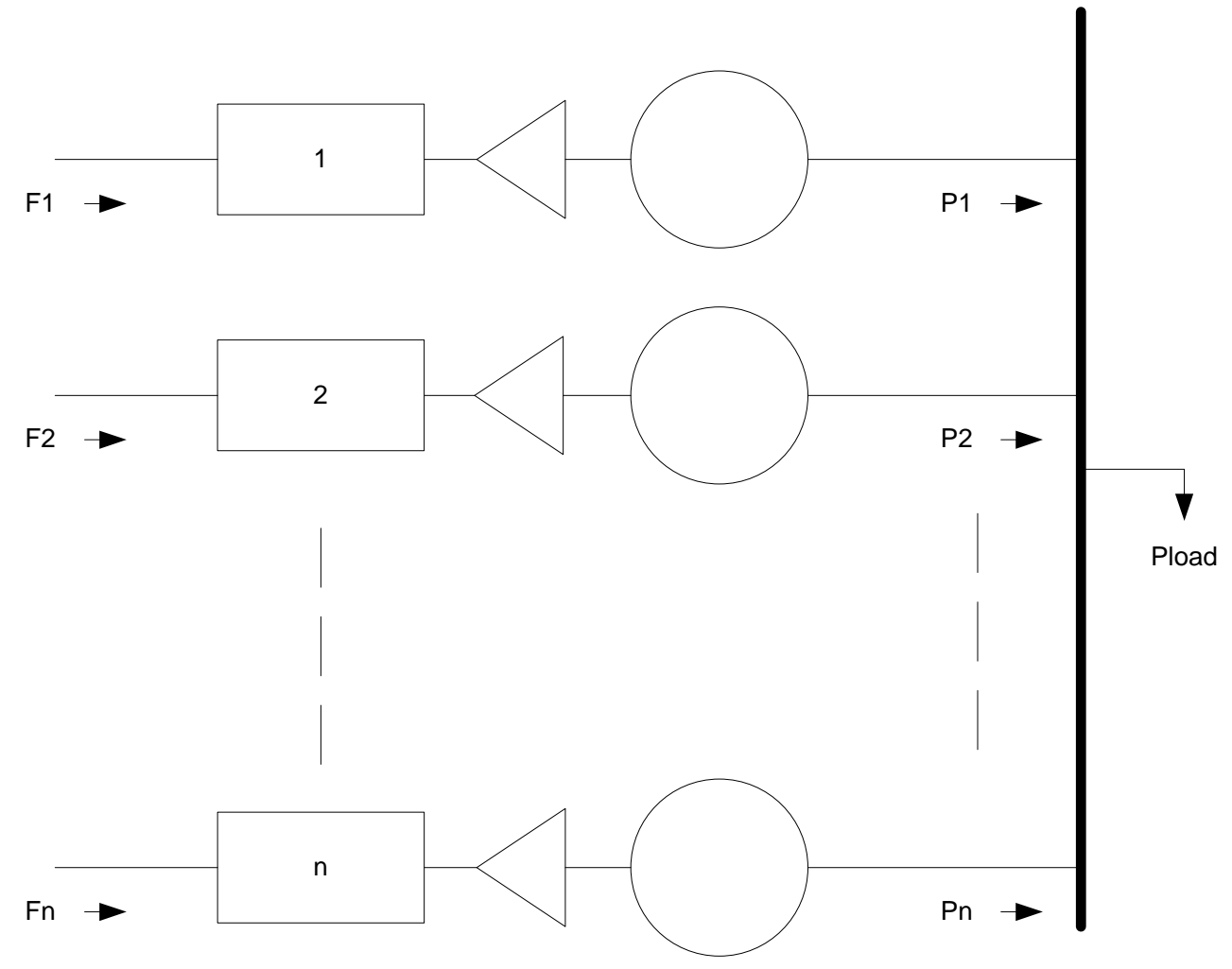

Figure 3-2: Dispatch to a Load with $n$ Thermal Generators [25]

The overall cost of the system is described by the equation 3.6

$$
F_{T}=F_{1}+F_{2}+\ldots+F_{n}=\sum_{i=1}^{n} F_{i}\left(P_{i}\right)
$$

Where $F_{1}, F_{2}, \ldots, F n$ are the cost functions for each of the $n$ generators and $P_{1}, P_{2}, \ldots, P_{n}$ are the respective output power values in MW. Most input-output curves are given in terms of input heat $\left(H_{i}\right)$ with respect to that source of generation's output power in MW. In the case in which the input-output curves are given in terms of input heat with respect to output power, the fuel cost must be multiplied by these equations to get the cost functions. These functions are constrained by a minimum and maximum output power values and minimum up and down times. The quadratic equations are used with Lagrange multipliers to find the most economical solution to the problem. The quadratic equation describing the cost of generation vs. output power for 
each generator represents the objective function in the economic dispatch problem. The summation of all of the output powers minus the total demand represents the constraint equation. From the theory of Lagrange multipliers in calculus (3.7) can be derived.

$$
\ell\left(P_{1}, P_{2}, \ldots, P_{n}, \lambda\right)=F_{T}\left(P_{1}, P_{2}, \ldots, P_{n}\right)+\lambda\left(P_{\text {load }}-\sum_{i=1}^{n} P_{i}\right)
$$

Where $\ell$ is the Lagrangian, $F$ is the objective function, $\lambda$ is the Lagrange multiplier and the constraint function is $P_{\text {load }}-\sum_{i=1}^{n} P_{i}$ as previously described. Taking the partial derivatives of the Lagrangian with respect to each individual power output yields (3.8).

$$
\begin{gathered}
\frac{\partial \ell\left(P_{1}, P_{2}, \ldots, P_{n}, \lambda\right)}{\partial P_{i}}=\frac{\partial F_{T}\left(P_{1}, P_{2}, \ldots P_{n}\right)}{\partial P_{i}}-\lambda=0 \\
\frac{\partial F_{T}}{\partial P_{i}}=\lambda
\end{gathered}
$$

Equation (3.8) can be rewritten as the system of equations given in (3.9).

$$
\begin{gathered}
\frac{\partial F_{T}}{\partial P_{1}}=\lambda \\
\frac{\partial F_{T}}{\partial P_{2}}=\lambda \\
\vdots \\
\frac{\partial F_{T}}{\partial P_{n}}=\lambda
\end{gathered}
$$

The above equations can be set up into matrix form by first analyzing the quadratic cost equations which represent the individual thermal generating units given in (3.10) 


$$
\begin{gathered}
F_{1}=a_{1}+b_{1} P_{1}+c_{1} P_{1}^{2} \\
F_{2}=a_{2}+b_{2} P_{2}+c_{2} P_{2}^{2} \\
\vdots \\
F_{n}=a_{n}+b_{n} P_{n}+c_{n} P_{n}^{2}
\end{gathered}
$$

Where $a_{i}, b_{i}$ and $c_{i}$ are the quadratic coefficients of the cost functions. Differentiating the cost functions with respect to their powers then yields (3.11).

$$
\begin{gathered}
\frac{\partial F_{1}}{\partial P_{1}}=b_{1}+2 c_{1} P_{1} \\
\frac{\partial F_{1}}{\partial P_{2}}=b_{2}+2 c_{2} P_{2} \\
\vdots \\
\frac{\partial F_{n}}{\partial P_{n}}=b_{n}+2 c_{n} P_{n}
\end{gathered}
$$

Using the Lagrange multipliers to solve the system for its minimum cost value gives (3.12).

$$
\begin{gathered}
b_{1}+2 c_{1} P_{1}=\lambda \\
b_{2}+2 c_{2} P_{2}=\lambda \\
\vdots \\
b_{n}+2 c_{n} P_{n}=\lambda
\end{gathered}
$$

The equation for the system's total power is needed so that the minimum cost value which satisfies the system demand can be calculated. The equation for the systems total demand i.e. the constraint equation is given in (3.13)

$$
P_{1}+P_{2}+\ldots+P_{n}=P_{\text {load }}
$$


Incorporating this equation into (3.12) and rearranging yields the system of equations given in (3.14)

$$
\begin{gathered}
2 c_{1} P_{1}-\lambda=-b_{1} \\
2 c_{2} P_{2}-\lambda=-b_{2} \\
\vdots \\
2 c_{n} P_{n}-\lambda=-b_{n} \\
P_{1}+P_{2}+\ldots+P_{n}=P_{\text {load }}
\end{gathered}
$$

Where the Lagrange multiplier $\lambda$ is the systems incremental cost rate. Its units are in $\$ / M W h$. Equation (3.14) can be written in matrix form and solved using linear algebra techniques. Equation (3.14) written in matrix form is as follows in (3.15).

$$
\left[\begin{array}{ccccc}
2 c_{1} & 0 & \cdots & 0 & -1 \\
0 & 2 c_{2} & \cdots & 0 & -1 \\
\vdots & \vdots & \ddots & \vdots & \vdots \\
0 & 0 & \cdots & 2 c_{n} & -1 \\
1 & 1 & \cdots & 1 & 0
\end{array}\right]\left[\begin{array}{c}
P_{1} \\
P_{2} \\
\vdots \\
P_{n} \\
\lambda
\end{array}\right]=\left[\begin{array}{c}
-b_{1} \\
-b_{2} \\
\vdots \\
-b_{n} \\
P_{\text {load }}
\end{array}\right]
$$

Solving the system for output power and the system incremental cost rate yields the matrix equation given in (3.16)

$$
\left[\begin{array}{c}
P_{1} \\
P_{2} \\
\vdots \\
P_{n} \\
\lambda
\end{array}\right]=\left[\begin{array}{ccccc}
2 c_{1} & 0 & \cdots & 0 & -1 \\
0 & 2 c_{2} & \cdots & 0 & -1 \\
\vdots & \vdots & \ddots & \vdots & \vdots \\
0 & 0 & \cdots & 2 c_{n} & -1 \\
1 & 1 & \cdots & 1 & 0
\end{array}\right]^{-1}\left[\begin{array}{c}
-b_{1} \\
-b_{2} \\
\vdots \\
-b_{n} \\
P_{\text {load }}
\end{array}\right]
$$

Equation (3.16) gives the values of power in MW for each generation source that produces the minimum cost and the most economical solution. The solution to (3.16) must fall 
within the minimum and maximum power constraints for each thermal generator. When the solution given by (3.16) gives an output power which falls out of the minimum or maximum power constraints the generation source which falls out of those constraints must be set to the minimum value if it is under the minimum power constraint and set to the maximum value if it is over the maximum power constraint. With this power set to the particular value which is within the power constraints its cost equation can be eliminated from the system and likewise a row can be eliminated from (3.16). The $n+1 \times n+1$ matrix is then reduced to an $n \times n$ matrix.

\subsubsection{Economic Dispatch With Transmission Losses}

The economic dispatch problem that is solved in this study does not incorporate the power losses that occur in transmission lines over a distance, however the theory should be briefly covered so that there is a good general understanding of the process because the effect of transmission losses will be discussed in the comparative analysis section. Figure 3-2 was adapted to show the systems transmission network and is illustrated in Figure 3-3.

In this figure, $\mathrm{TL}_{1}, \mathrm{TL}_{2}, \ldots, \mathrm{TL}_{\mathrm{n}}$ are the transmission lines that deliver the power to the single point bus for their respective thermal generators. These transmission lines are composed of a resistive and an inductive series element and two shunt capacitors.

As one would imagine, when electricity flows throw transmission lines over a long distance there are losses that affect the economic dispatch solution. Due to this fact it is fairly obvious that the less distance that electricity must travel through transmission lines the more economical a solution will be. This will be important when considering the economic solution with gas turbine generators which are at relatively greater distances from distribution substations than energy storage devices which can be placed very close to the substations. 


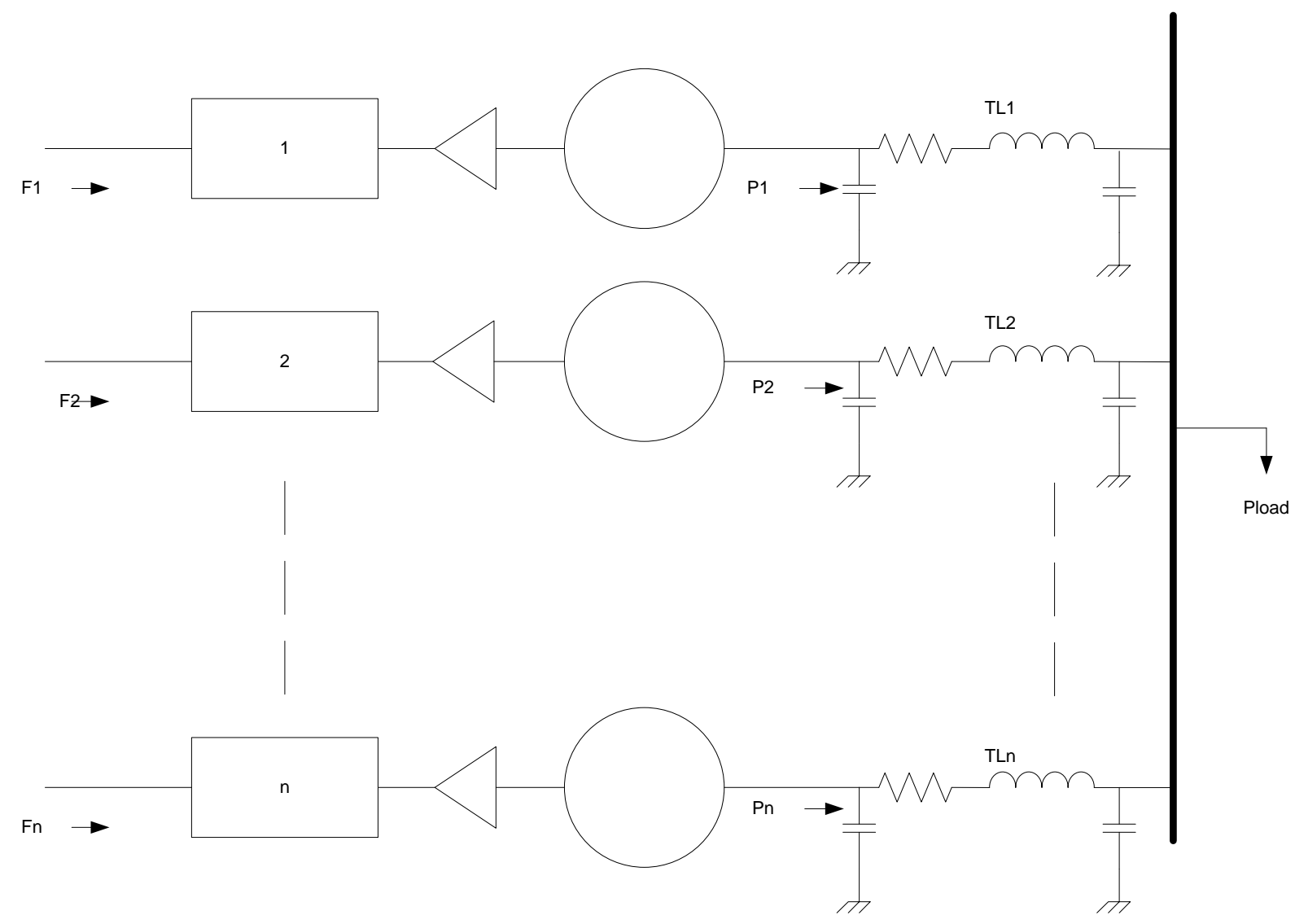

Figure 3-3: Dispatch to a Load with $n$ Generators and Transmission Losses

The same process can be used to calculate the optimal solution for each thermal turbine generator for the case in which transmission losses are included with the exception of one particular difference. The objective function remains the same as in the case where transmission losses are included but the constraint equation changes. The new constraint equation is given in (3.17).

$$
P_{\text {load }}+P_{\text {loss }}-\sum_{i=1}^{n} P_{i}=0
$$

Inserting the new constraint equation into the Lagrangian we can rewrite (3.7) and get (3.18). 


$$
\ell\left(P_{1}, P_{2}, \ldots, P_{n}, \lambda\right)=F\left(P_{1}, P_{2}, \ldots, P_{n}\right)+\lambda\left(P_{\text {load }}+P_{\text {loss }}-\sum_{i=1}^{n} P_{i}\right)
$$

Both the methods are nearly identical with the exception of the constraint equation but it is clear from (3.17) that the solution will be different with losses than without losses. Incorporating transmission losses into the problem in turn increases the incremental cost rate and in turn provides a more costly solution [26]

\subsection{OPTIMIZING ENERGY STORAGE WITH DYNAMIC PROGRAMING}

Dynamic programing is often referred to as the "brute force" method of finding the optimal solution to a problem. The reason for this is that dynamic programming simply tries every possible "avenue" to achieve the desired objective of the problem. Basically dynamic program is the method of solving a large problem by breaking it up into sets of much smaller sub-problems [27]. Dynamic programming can be a very effective and powerful tool for optimization, especially with the use of computers to carry it out.

Figure 3-3 illustrates a one dimensional dynamic programming example [28]. The objective is to reach node $N$ starting from node $A$ by covering the shortest distance. The number above each line which connects one node to another node is the distance between each node using that particular path. The goal of getting from node $N$ to node $A$ by covering the shortest possible distance in this example is the large problem which is to broken down into much smaller sub-problems. The distance travelled from one node to the next in this example is the subproblem. 


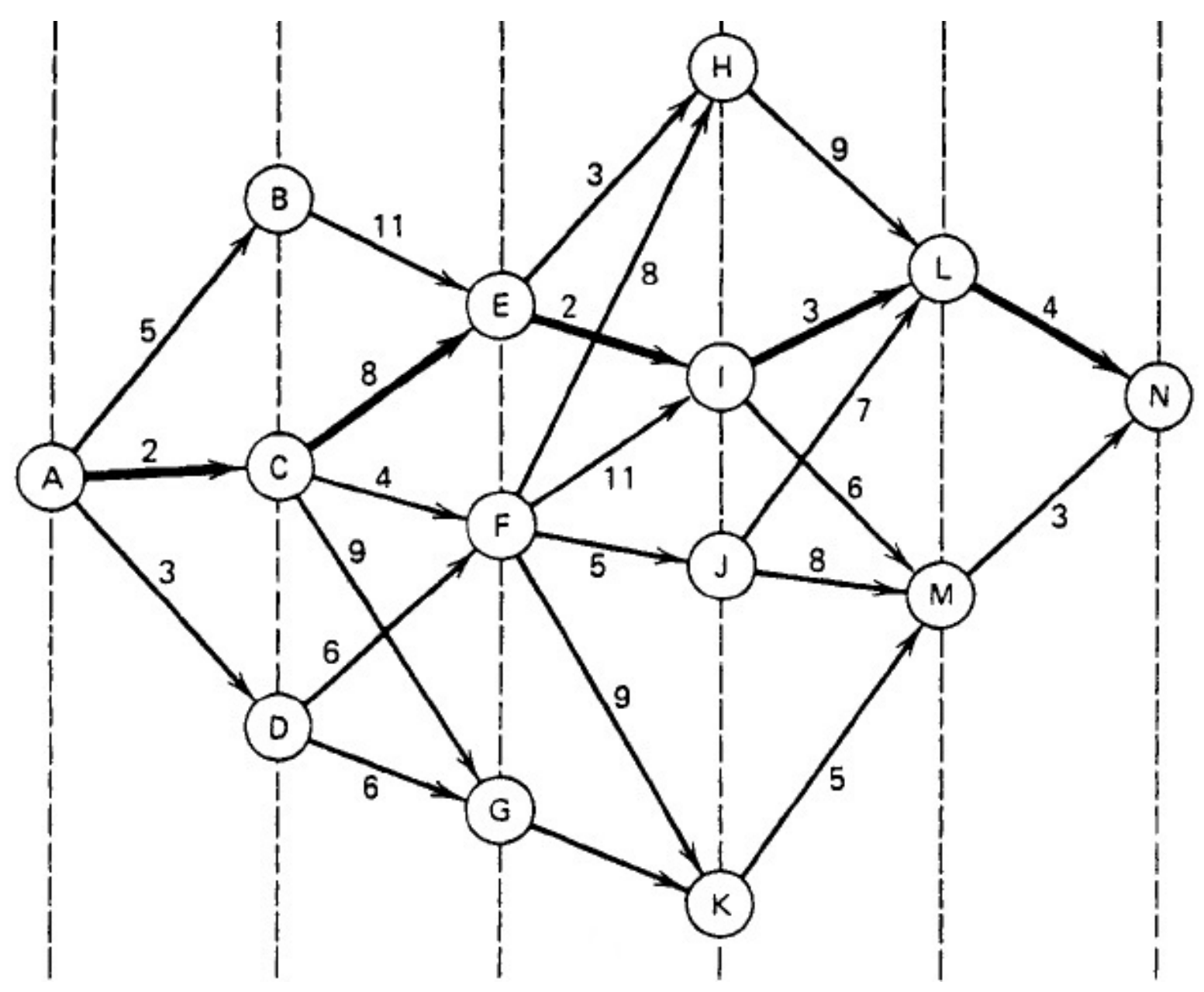

Figure 3-4: Example of a Dynamic Programming Problem [25]

Note that the best solution for a sub-problem might not be the best solution for the large problem which is to be solved. For example the best possible solution to this dynamic programming example is the path ACEILN. However, the sub-problem of travelling from node $C$ to the next possible node has the best solution of $C F$ with a total distance of 4 which is different to the best possible solution to the overall problem. Travelling from node $C$ to node $N$ by way of node $E$ has best possible solution CEILN which covers a distance of 17 as opposed to travelling from node $C$ to node $N$ by way of node $F$ has best possible solution $C F J L N$ or $C F J M N$ 
which both cover a distance of 20 . So even though the solution to a sub-problem may be the best possible solution it must be evaluated in terms of the overall solution to see its effectiveness.

\subsubsection{Dynamic Programming Application in Power Systems}

Richard Bellman had originally used dynamic programming which would later be recognized by the IEEE as a systems analysis and engineering topic [29]. Bellman and Dreyfus coined the "Principal of Optimality" which states "An optimal policy has the property that whatever the initial state and decision are, the remaining decisions must constitute an optimal policy with regard to the state resulting from the first decision. [30]"

Dynamic programing has been used for many engineering applications and is particularly useful in electric power engineering. With the increasing amount of renewable generation that is tied into the grid comes the task of allocating the power that is generated from these renewables effectively. Energy generated from renewables such as wind and solar must be either used as it is generated or stored. Dynamic programming with the help of scientific computing can be used to find the most cost effective method of allocating energy through storage devices.

An example of dynamic programming for the allocation of energy is given in Figure 3-5. This example was taken from [37] and represents two energy storage units which must allocate their stored energy by the most cost effective methods. The state of the storage is represented by a two bit binary number. For storage unit $\mathrm{R}$ and storage unit $\mathrm{Q}$ there is a possibility of three different next states possible. The next state which has the cheapest minimum cost path will be

chosen for each of the storage units. This process continues on for the next twenty three hours of the day. In this example one day is covered. The initial state is when $t$ is equal to zero and the final state is when $t$ is equal to twenty four i.e. when $t$ is equal to zero for the next day. 


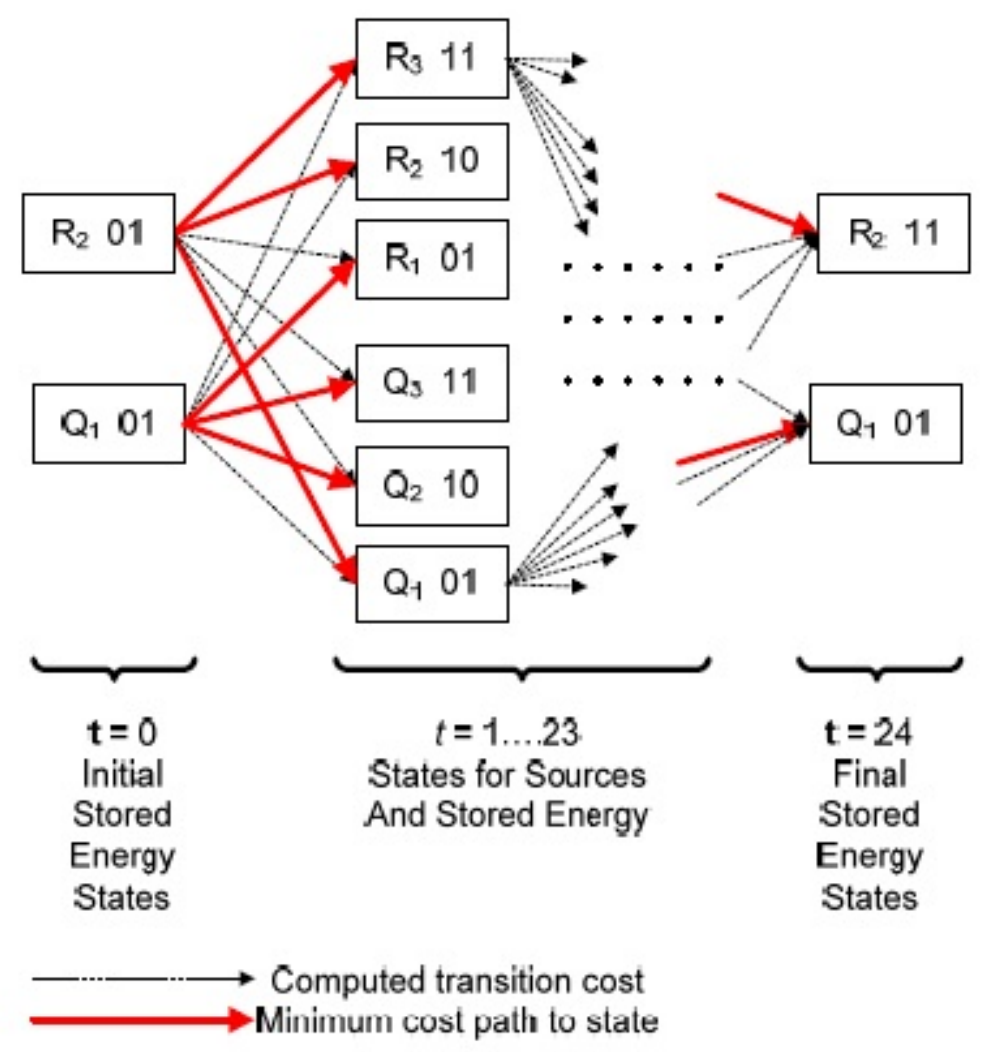

Figure 3-5: Allocation of Energy Storage by Dynamic Programming [37]

\subsection{UNIT COMMITMENT}

Unit commitment refers to the physical and economic constraints that are placed on thermal generation units and the best solution available while following these constraints. In this section some of the constraints that thermal generation units have will be discussed as well as solutions to these constraints. 


\subsubsection{Maximum or Minimum Change in Output Power}

Thermal generation units have a maximum and minimum amount of output power that they can change per time step. Thermal generation units have a heat input which yields a power output through turbine generators. The output power is changed by increasing or decreasing the input heat and in turn increases the steam flow to the turbine. Certain generators can change speed slower or faster than others and therefore there is constraint on this change.

\subsubsection{Start-Up Time}

Thermal generation units must be brought up to the proper operating speed so the system is synchronized to the system load. As one would expect, it takes a bit of time to reach this proper operating speed. The time that it takes for the turbine generator to be brought up to operating speed is referred to as the start-up time constraint.

\subsubsection{Spinning Reserve}

Spinning reserve is a solution to the start-up time constraint. For instance, gas turbine generators are very useful for their fast response time. However, they are very expensive so it does not make economic sense to have them connected to the load at all times. The solution to this is to have them running in spinning reserve mode where they are up and running but without any load connected to them. This still comes at a cost, but a much smaller cost than if they were operating with a load connected. 


\subsubsection{Minimum Up and Down Times}

Lastly, another constraint that must be considered is the minimum up and down times that a generator has. A thermal generator works on the principal of fuel being burned to create heat and in turn steam which turns the turbine. This process dictates that a generator once up and running can’t be immediately shut down and conversely a generator once shut down can’t be immediately started up again. 


\subsection{PROBLEM SETUP AND SOLUTION}

This chapter uses the techniques used in Chapters 2.0 and 3.0 to set up the economic dispatch problem both in the case with grid level energy storage for peak shaving and without it. The problem is set up such that there are three generation units of different types. The single point bus that was discussed in Section 3.1 is fed by a coal fired generator, and oil fired generator and a gas turbine generator. Energy storage is also incorporated into the problem for the use of load leveling as was discussed in Chapter 2.0. Figure 3-2 is adapted to fit the problem and is illustrated in Figure 4-1.

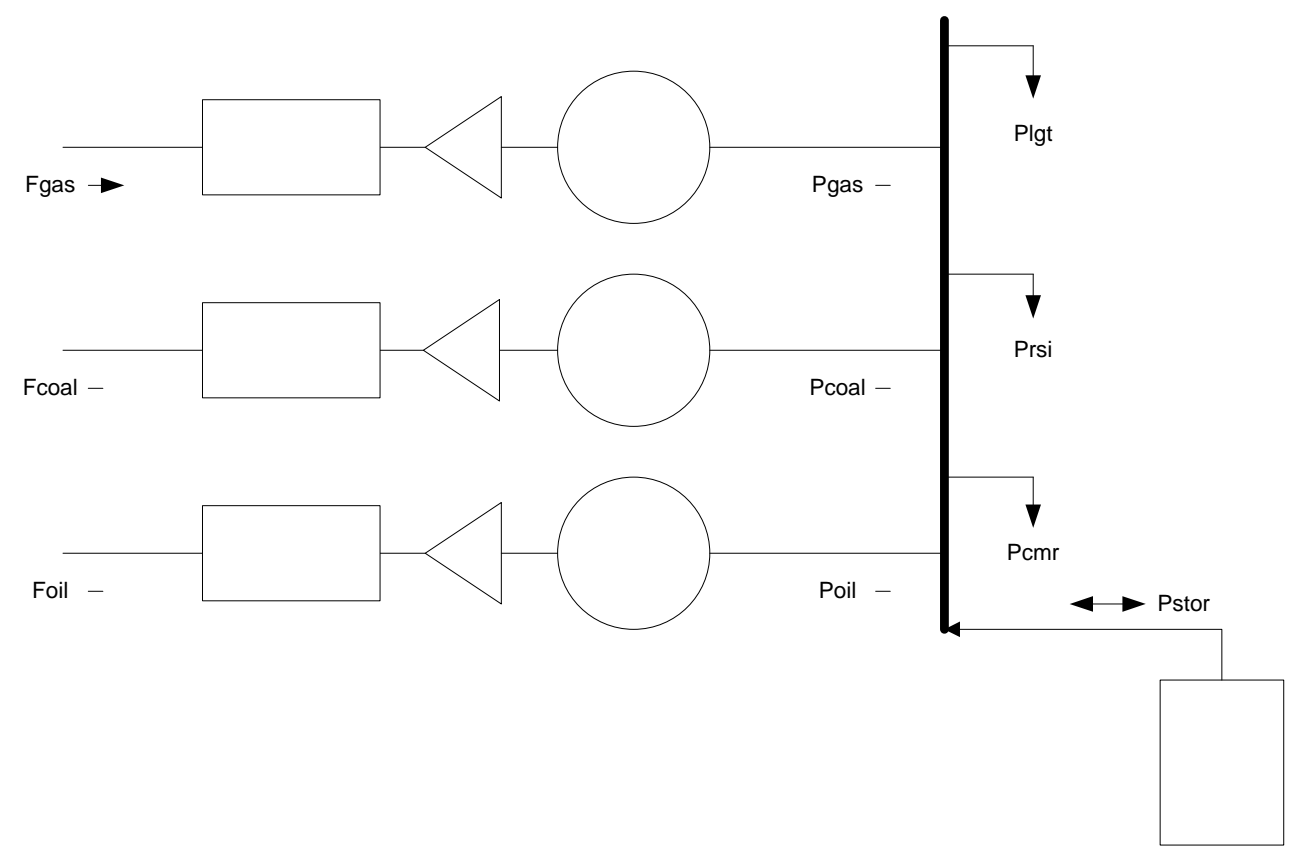

Figure 4-1: Economic Dispatch Problem with Coal, Oil and Gas Thermal Generators and the Integration of Energy Storage 
One of the goals of this study is to show the economic benefit of using energy storage to replace the use of gas turbine generators. Gas turbine generators can react to a change in system load much faster than other fossil fuel fired generators and so they are required. Some studies show that gas turbine generators can actually react to a change in load as much as ten times faster than other fossil fuel fired thermal generators [31]. This is one of the greatest benefits of gas turbine generators. The problem with gas turbine generators is that they are much more expensive to use than other fossil fuel fired thermal generators [25]. It is proposed in this study that large grid level energy storage systems can be used to flatten the load so it is smooth enough so that the use of gas turbine generators is not required.

Another benefit of using energy storage to replace gas turbine generators, which is not as obvious, is the reduction in emissions. All of the fossil fuel thermal generators that are discussed in this study produced greenhouse gas emissions. The emissions produced by coal, oil and gas are given in Table 4-1.

Table 4-1: Pollutants Generated By Fossil Fuel Electricity Generation [32]

\begin{tabular}{|c|c|c|c|c|c|}
\hline Pollutant & Hard Coal & Brown Coal & Fuel Oil & Other Oil & Gas \\
\hline $\mathrm{CO}_{2}$ (g/GJ) & 94600 & 101000 & 77400 & 74100 & 56100 \\
\hline $\mathrm{SO}_{2}$ (g/GJ) & 765 & 1361 & 1350 & 228 & 0.68 \\
\hline $\mathrm{NO}_{\mathrm{x}}$ (g/GJ) & 92 & 183 & 195 & 129 & 93.3 \\
\hline $\mathrm{CO}$ (g/GJ) & 89.1 & 89.1 & 15.7 & 15.7 & 14.5 \\
\hline $\begin{array}{c}\text { Non methane organic } \\
\text { compounds (g/GJ) }\end{array}$ & 4.92 & 7.78 & 3.70 & 3.24 & 1.58 \\
\hline $\begin{array}{c}\text { Particulate matter } \\
\text { (g/GJ) }\end{array}$ & 1203 & 3254 & 16 & 1.91 & 0.1 \\
\hline $\begin{array}{c}\text { Flue gas volume total } \\
\left.\text { (m }{ }^{3} / \mathrm{GJ}\right)\end{array}$ & 360 & 444 & 279 & 279 & 272 \\
\hline
\end{tabular}


It may seem like there is an increase in emissions due to the fact that the storage absorbs power while it's charging and this power is supplied by the coal and oil generators which give off more pollutants than gas turbine generators. However, most of the power that is supplied to the storage device is supplied by the coal generator and with clean coal technology such as carbon capturing becoming ever more prevalent in the industry a good portion of the pollutants that are produced from coal fired generation can be removed before they enter the atmosphere [33].

Another goal of this study is to observe and analyze the effect that a smoother, flatter load has on the cost of dispatching the power to supply it. Reducing changes in the load per time step could potentially reduce the cost because of the elimination of gas turbines but another question that can be answered is how that affects the other generators.

In this chapter the thermal generation cost curves which are to be used in the economic dispatch problem are modeled, the system load is modeled, the charging and discharging profiles for the storage units are modeled, storage allocation is optimized and the economic dispatch problem is set up.

\subsection{THERMAL GENERATION UNITS}

The thermal generation units used in this study are coal, oil, and gas turbine generators. Each generator is represented by its own heat vs. power curve. The heat vs. power curves are multiplied by their respective fuel costs to obtain the fuel cost curves which are cost per hour as a function of power in MW. The heat vs. power curves for the coal and oil generation are given in (4.1)-(4.3) [25]. 


$$
\begin{array}{ll}
H_{\text {coal }}\left(P_{\text {coal }}\right)=510.0+7.92 P_{\text {coal }}+0.00142 P_{\text {coal }}^{2} & 344 M W \leq P_{\text {coal }} \leq 1377 M W \\
H_{\text {oil }}\left(P_{\text {oil }}\right)=78.0+7.97 P_{\text {oil }}+0.00482 P_{\text {oil }}^{2} & 115 M W \leq P_{\text {oil }} \leq 459 M W \\
H_{\text {gas }}\left(P_{\text {gas }}\right)=300.0+6.0 P_{\text {gas }}+0.0025 P_{\text {gas }}^{2} & 115 M W \leq P_{\text {gas }} \leq 918 M W
\end{array}
$$

The fuel costs for coal and oil are given in units of $\$ / M B t u$ and can be seen in Table $4-2$. The fuel cost of gas is given in units of $\$ / \mathrm{ccf}$ and must be converted to units of $\$ / \mathrm{MBtu}$. The cost of gas is $2.0 \$ / \mathrm{ccf}$ and is converted to $\$ / \mathrm{MBtu}$ in (4.4).

$$
\frac{\$ 2.0}{c c f} \times \frac{1 c c f}{10^{3} \mathrm{ft}^{3}} \times \frac{1 \mathrm{ft}^{3}}{1100 \mathrm{Btu}} \times \frac{10^{6} \mathrm{Btu}}{1 \mathrm{MBtu}}=\frac{\$ 1.8182}{M B t u}
$$

The following table illustrates the fuel cost for all three types of generation

Table 4-2: Fuel Costs for Thermal Generation Units [25]

\begin{tabular}{|l|l|}
\hline Coal Unit: & fuel cost $=1.1 \$ / \mathrm{MBtu}$ \\
\hline Oil Unit: & fuel cost $=1.0 \$ / \mathrm{MBtu}$ \\
\hline Gas Unit: & fuel cost $=1.8182 \$ / \mathrm{MBtu}$ \\
\hline
\end{tabular}

Multiplying the fuel costs by the heat vs. power curves gives the fuel cost vs. power curves which are to be optimized using Lagrange multipliers. The fuel cost vs. power curves for each of the thermal generators is given in (4.5)-(4.7).

$$
\begin{array}{ll}
F_{\text {coal }}\left(P_{\text {coal }}\right)=H_{\text {coal }}\left(P_{\text {coal }}\right) \times 1.1=561+7.92 P_{\text {coal }}+0.001562 P_{\text {coal }}^{2} & \$ / \mathrm{h} \\
F_{\text {oil }}\left(P_{\text {oil }}\right)=H_{\text {oil }}\left(P_{\text {oil }}\right) \times 1.0=78+7.97 P_{\text {oil }}+0.00482 P_{\text {oil }}^{2} & \$ / \mathrm{h} \\
F_{\text {gas }}\left(P_{\text {gas }}\right)=H_{\text {gas }}\left(P_{\text {gas }}\right) \times 1.8182=545.45+10.909 P_{\text {gas }}+0.0045 P_{\text {gas }}^{2} & \$ / \mathrm{h}
\end{array}
$$




\subsection{SETTING UP THE UNIT COMMITMENT}

As was discussed in the introduction to this section gas turbine generators can react to a change in load much faster than fossil fuel fired thermal generators. In this study the gas turbine generators react three times faster than the coal and oil fired generators. This relationship is given in (4.8) and (4.9).

$$
\begin{gathered}
\left|P_{\text {coal/oil } n+1}-P_{\text {coal /oil } n}\right| \leq 150 \mathrm{MW} \\
\left|P_{\text {gas } n+1}-P_{\text {gas } n}\right| \leq 450 \mathrm{MW}
\end{gathered}
$$

There are also limitations to how long a generator can be on as well. The gas turbine generator is the most expensive to run and therefore the best and most economical solution is one that does not use the gas turbine generators. However, due to drastic load changes and very large load peaks, gas turbines are necessary. Table 4-3 gives the generator constraints that must be followed in order to commit the units.

Table 4-3: Gas Turbine Generation Unit Commitment Constraints [25]

\begin{tabular}{|c|c|c|c|c|c|c|}
\hline Unit & Min. Up & Min. Down & Spinning & Hot Start & Cold Start & Cold Start \\
& Time & & Reserve & Cost & Cost & Time \\
\hline Gas & 4 hours & 4 hours & $545.45 \$ / \mathrm{h}$ & $\$ 150$ & $\$ 350$ & 4 hours \\
Turbine & & & & & & \\
\hline
\end{tabular}




\subsection{MODELING THE SYSTEM LOAD}

The system load data was gathered from [34]. The data represents the commercial, residential and street lighting sectors of a rural area with a large commercial area. A rural load was chosen for this study because there is usually plenty of area to install large scale energy storage units around substations that feed rural loads. It should be noted that the load would be very different if it were in an urban area or if it were in a rural area with a predominantly industrial load. The load is given per hour in Table 4-4.

Table 4-4: System Daily Demand [34]

\begin{tabular}{|c|c|c|c|c|}
\hline Hour & $\begin{array}{l}\text { Lighting } \\
(\mathrm{MW})\end{array}$ & $\begin{array}{l}\text { Residential } \\
\text { (MW) }\end{array}$ & $\begin{array}{l}\text { Commercial } \\
(\mathrm{MW})\end{array}$ & $\begin{array}{r}\text { Total } \\
(\mathrm{MW})\end{array}$ \\
\hline 0000 & 100 & 250 & 300 & 650 \\
\hline 0100 & 100 & 250 & 300 & 650 \\
\hline 0200 & 100 & 250 & 300 & 650 \\
\hline 0300 & 100 & 250 & 300 & 650 \\
\hline 0400 & 100 & 250 & 300 & 650 \\
\hline 0500 & 100 & 250 & 300 & 650 \\
\hline 0600 & 100 & 250 & 300 & 650 \\
\hline 0700 & 0 & 350 & 300 & 650 \\
\hline 0800 & 0 & 450 & 400 & 850 \\
\hline 0900 & 0 & 550 & 600 & 1150 \\
\hline 1000 & 0 & 550 & 1100 & 1650 \\
\hline 1100 & 0 & 550 & 1100 & 1650 \\
\hline 1200 & 0 & 600 & 1100 & 1700 \\
\hline 1300 & 0 & 600 & 1100 & 1700 \\
\hline 1400 & 0 & 600 & 1300 & 1900 \\
\hline 1500 & 0 & 600 & 1300 & 1900 \\
\hline 1600 & 0 & 600 & 1300 & 1900 \\
\hline 1700 & 0 & 650 & 1300 & 1950 \\
\hline 1800 & 0 & 750 & 900 & 1650 \\
\hline 1900 & 0 & 900 & 500 & 1400 \\
\hline 2000 & 100 & 1100 & 500 & 1700 \\
\hline 2100 & 100 & 1100 & 500 & 1700 \\
\hline 2200 & 100 & 900 & 300 & 1300 \\
\hline 2300 & 100 & 700 & 300 & 1100 \\
\hline
\end{tabular}


Each load is unique due to its nature and adds an interesting aspect to the problem compared with a load which is not broken up into components. Figure 4-2 depicts graphically how these different loading types behave over the course of the day. The behavior of these loads is of particular interest between 0000 and 0700 in which the total load does not change and is the lowest value during the day. This will be the most opportune time to increase the load on the residential and commercial sectors by charging the storage devices. These charged storage devices will be used later in the day when the system demand is very high. In this example the times in which the total system load is the highest is in the late afternoon to evening. This is fairly accurate with any realistic daily demand due to the high volume of energy use during the late afternoon in the commercial sector and during the evening in the residential sector. Figure 4-2 is a MATLAB generated plot which illustrates the daily demand curve with respect to the hour of the day.

It can be seen from Figure 4-2 that this load is of the double peak type. At 1700 the system load reaches its maximum value and then decreases for the next couple of hours. The load then rises again and hits a second peak at 2000. The first peak is caused by the rush and the second peak is caused by everyone returning home in the residential sector. This can be seen in Figure 4-2 where the residential sector increases its greatest amount from 1700 to where the second peak occurs at 2000 .

There are several different load profiles that exist. Some load profiles only have one load peak rather than two. However, this load profile is typical of most loads, especially those that have a large residential component. The load used in this study is illustrated as follows in Figure $4-2$. 


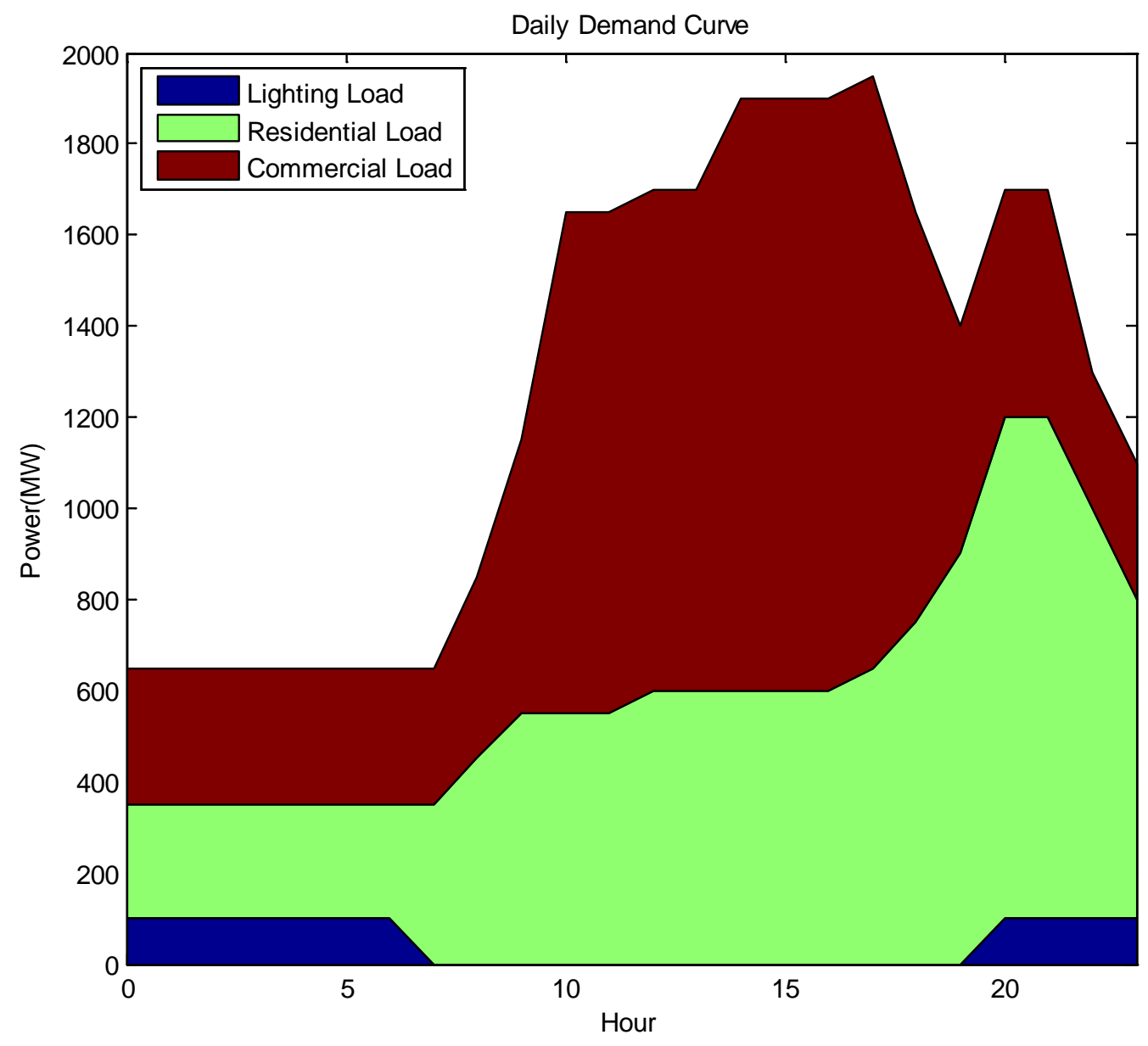

Figure 4-2: System Daily Demand Curve 


\subsection{MODELING THE ENERGY STORAGE}

After considering all of the different types of energy storage that were discussed in Section 2.2, the most logical choice to use was either NaS batteries or pumped storage. NaS batteries have nearly all of the advantages that the other forms of storage have without many of the disadvantages. The one advantage that the NaS battery lacks over other forms of storage is the capacity for a very large system power rating. However, the only forms of storage that have a greater capacity for a very large system power rating is pumped storage and CAES. CAES was not used in this study because of its commercial immaturity and the emissions that it gives off. Table 4-5 shows a comparison of $\mathrm{NaS}$ batteries against $\mathrm{L} / \mathrm{A}, \mathrm{VRB}$ and $\mathrm{Z} / \mathrm{Br}$ batteries. A graphical representation of Table 4-5 can be seen in Figure 4-3.

Table 4-5: Feasibility Scores of Grid Level Batteries [1]

\begin{tabular}{|c|c|c|c|c|}
\hline Required Features & NaS & L/A & $\mathbf{Z} / \mathbf{B r}$ & VRB \\
\hline Adequate Power Rating & 10 & 10 & 6 & 4 \\
\hline High Energy Efficiency & 10 & 6 & 7 & 8 \\
\hline Low Disposal Cost & 7 & 10 & 7 & 7 \\
\hline 4 to 10 hrs of Energy at Rated Power & 8 & 6 & 5 & 10 \\
\hline Low Total Installed Cost & 9 & 10 & 7 & 6 \\
\hline Low Relocation Cost & 9 & 7 & 10 & 4 \\
\hline Commercial Maturity & 7 & 10 & 3 & 3 \\
\hline Adequate Cycle Life & 10 & 1 & 6 & 9 \\
\hline Adequate Calendar Life & 10 & 3 & 5 & 6 \\
\hline Financial Strength of Supplier & 9 & 10 & 1 & 1 \\
\hline Lower Maintenance Cost & 10 & 1 & 5 & 5 \\
\hline Low Installed Footprint & 10 & 1 & 6 & 3 \\
\hline Total Feasibility Score & 108 & 75 & 68 & 66 \\
\hline
\end{tabular}




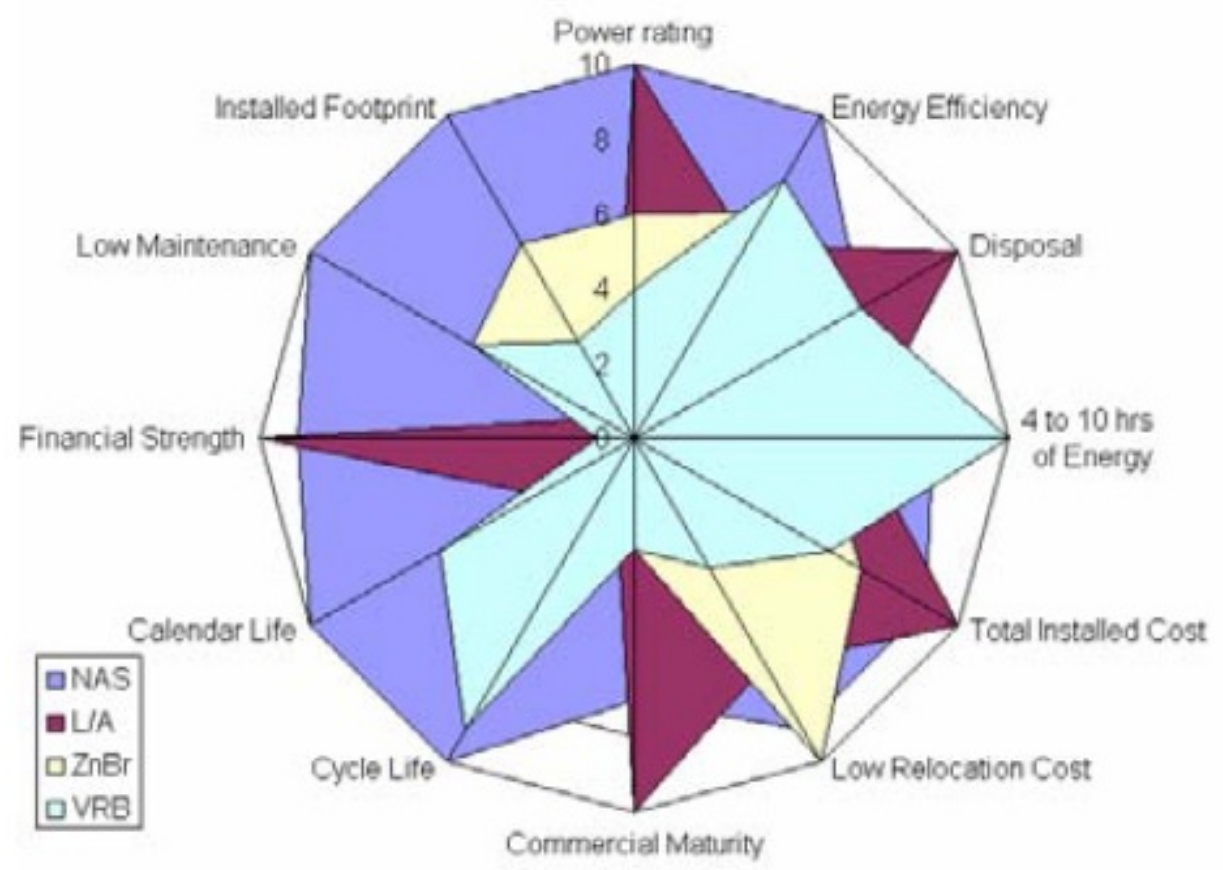

Figure 4-3: Feasibility Diagram of Grid Level Batteries [1]

The objective of this study was to show the effect that a large $600 \mathrm{MW}$ storage device has on the system load. For the case in which NaS batteries are used the storage device is broken up into five $120 \mathrm{MW}$ facilities, three in the commercial sector and two in the residential sector. However, NaS batteries can only have a system power rating of about 10 MW [1]. Twelve NaS batteries are configured in parallel which represent a $120 \mathrm{MW}$ NaS battery farm. One of the benefits of using batteries is that if there is enough room, then any power rating can be obtained simply by configuring the batteries in parallel.

Batteries are also beneficial because their operation is scalable. The charging and discharging rates of $10 \mathrm{MW}$ NaS batteries were modeled by scaling the charging and discharging rates of the $1 \mathrm{MW}$ batteries used by the AEP in [1]. Figure 4-4 illustrates the charging and discharging rates for 1 MW NAS batteries. These charging and discharging rates are continuous 
and must be discretized in order to allocate the energy that is stored. In this study, the system load profile is in increments of one hour so the storage devices must be discretized in increments of one hour.

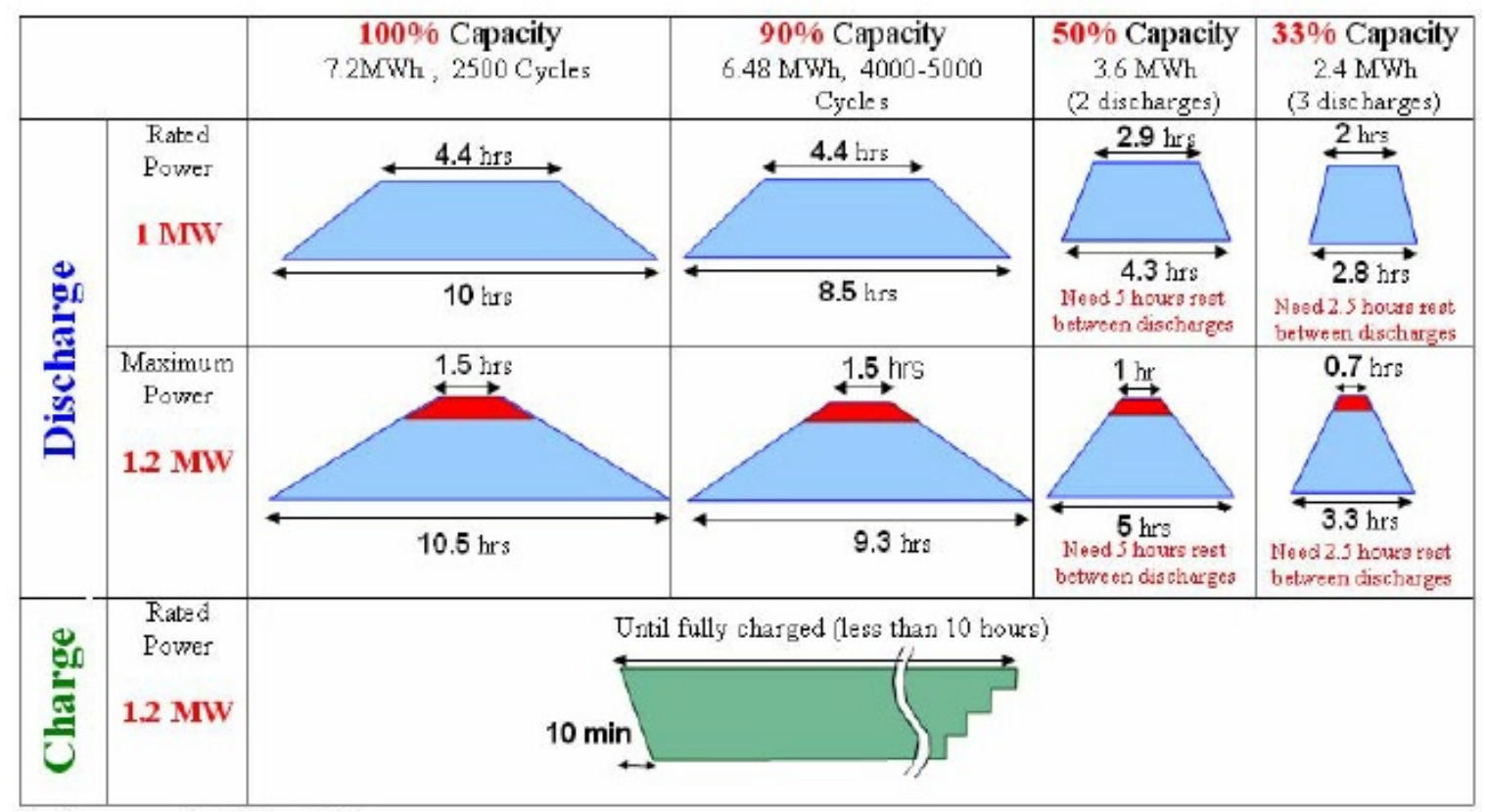

Figure 4-4: Charging and Discharging Profiles for 1 MW NaS Battery [1]

It can be seen from Figure 4-4 that the discharging profiles can be broken up into a piecewise function which is composed of a monotonically increasing linear function, a constant function and a monotonically decreasing linear function. The discharging profile is power in MW as a function of time in hours. The charging profile has a small ten minute section which is linear and then the function remains constant for the remainder of the charging. Because this linear function is relatively small in comparison to the total charging the assumption is made that the charging profile can be modeled as a constant charging at rated power. The discharging function had to be modeled as a linear piecewise function. Figure 4-5 illustrates the general discharging profile as a piecewise function. 


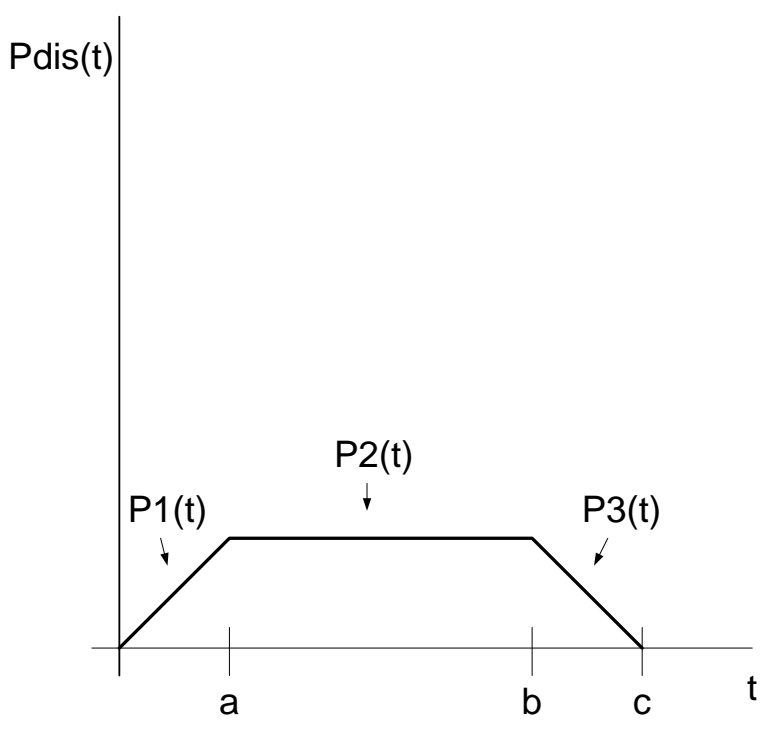

Figure 4-5: Discharging Profile as a Piecewise Function of Power vs. Time

The discharge profile function, $P_{d i s}$, is composed as a piecewise linear function that is given in (4.10).

$$
P_{\text {dis }}(t)=\left\{\begin{array}{cc}
\frac{P_{1}(a)}{a} t & 0 \leq t \leq a \\
P_{2}(a) & a \leq t \leq b \\
\left(\frac{P_{3}(c)-P_{3}(b)}{c-b}\right)(t-b)+P_{3}(b) & b \leq t \leq c
\end{array}\right.
$$

Figure 4-4 shows the discharging profiles for depths of discharge of $100 \%, 90 \%, 50 \%$ for two discharges and 33\% for three discharges. 90\% depth of discharge was chosen for this study due to the extended cycle life that is provides compared with that of $100 \%$ depth of discharge. Figure 4-4 does not give a profile for $45 \%$ depth of discharge for two discharges and so some assumptions must be made to acquire it. From Figure 4-4 it can be seen that the tops of the trapezoidal load profiles for $100 \%$ depth of discharge and $90 \%$ depth of discharge are an equal 
value of 4.4 hours. However, the bottoms of the load profiles are different at a value of 10 hours for $100 \%$ depth of discharge and 8.5 hours at $90 \%$ depth of discharge. The assumption was made that the difference between the load profiles of 50\% depth of discharge and $45 \%$ depth of discharge would follow the same pattern. The bottom of the load profile for $90 \%$ depth of discharge is $85 \%$ of the bottom of the load profile for $100 \%$ depth of discharge. Multiplying the bottom of the load profile for $50 \%$ depth of discharge by 0.85 then gives the bottom of the load profile for $45 \%$ depth of discharge with a value of 3.655 hours. The load profile for $45 \%$ depth of discharge can be seen in Figure 4-6.

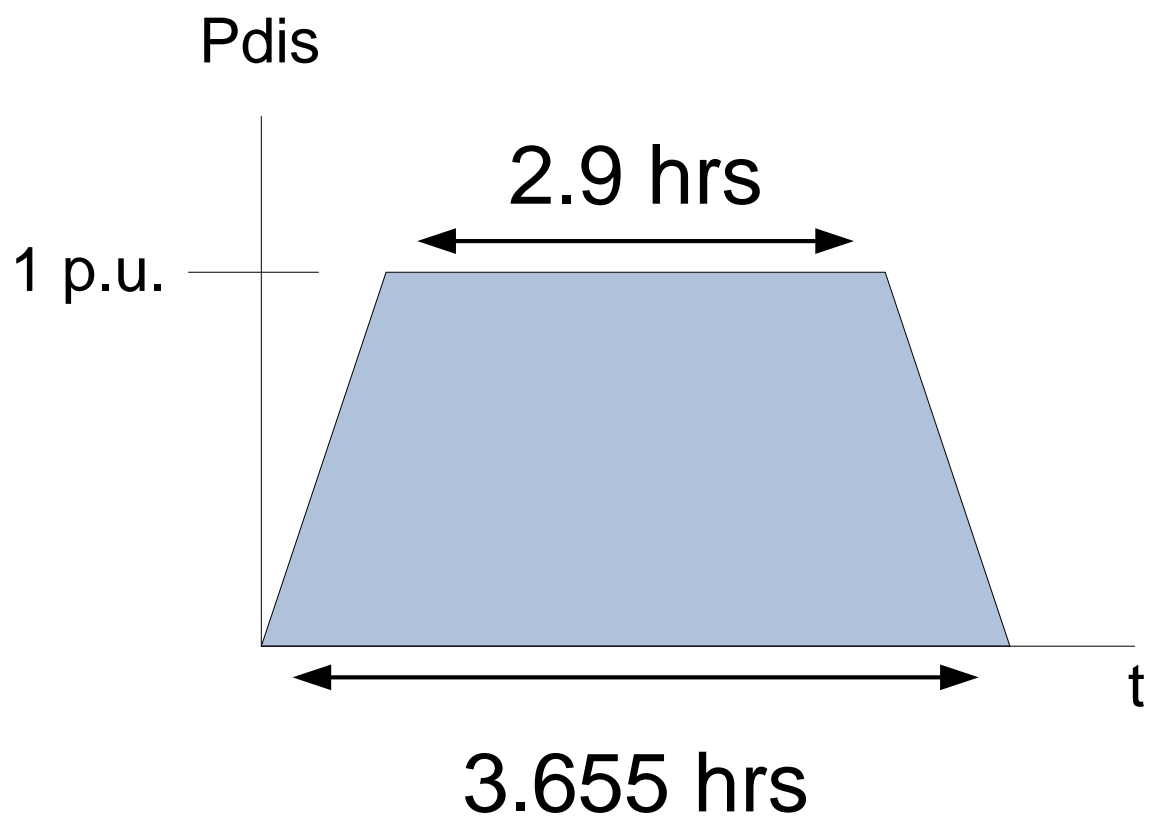

Figure 4-6: Discharging Profile for 45\% Depth of Discharge

The piecewise linear function for the $90 \%$ depth of discharge and the piecewise linear function for the $45 \%$ depth of discharge were calculated using (4.10) and are given in (4.11) and (4.12). 
For $90 \%$ depth of discharge:

$$
P_{\text {dis }}(t)=\left\{\begin{array}{cc}
0.4878 t & 0 \leq t \leq 2.05 \\
1 & 2.05 \leq t \leq 6.45 \\
-0.4878 t+4.1463 & 6.45 \leq t \leq 8.5
\end{array}\right.
$$

For 45\% depth of discharge:

$$
P_{\text {dis }}(t)=\left\{\begin{array}{cc}
2.649 t & 0 \leq t \leq 0.3775 \\
1 & 0.3775 \leq t \leq 3.2775 \\
-2.649+9.6821 & 3.2775 \leq t \leq 3.9
\end{array}\right.
$$

Calculating the definite integral of these piecewise functions yields the total energy that is discharged over the time range of the discharging profile in units of MWh. If these definite integrals are broken up hourly then the definite integral for a one hour period can be divided by one hour and will yield the average power for that particular hour. Equation (4.13) gives the discretized power supplied by the battery for the $k$ th hour of the discharging process where $n$ is discrete time in hours

$$
P_{d i s}[k]=\frac{\int_{n}^{n+1} P_{d i s}(t) d t}{1 h}
$$

This equation can be verified for correctness by calculating the total energy stored in the battery and comparing it to the given value. The total energy that is stored in the battery is given in (4.14).

$$
\text { total energy }=\sum_{k=0}^{k_{\max }} 1 h \times P_{d i s}[k]=\sum_{k=0}^{k_{\max }} \int_{n}^{n+1} P_{d i s}(t) d t
$$

Where $k_{\max }$ is the last hourly discrete time period in the discharging process of the battery. This equation was used to verify that the average power for each hour was correct. Figure 4-7 illustrates the discharging processes of the battery in discrete time for the $90 \%$ depth of discharge 
and the $45 \%$ depth of discharge cases. These average power values are given in Table 4-6. It should be noted that for the $45 \%$ depth of discharge case, the battery is done charging after hour 3 and hence has an average value of zero MW for hours 4 through 8.

Table 4-6: Average Discharging Power per Hour

\begin{tabular}{|c|c|c|}
\hline Hour & $\begin{array}{c}\text { Average Power (MW) for } \\
\text { 45\% Depth of Discharge }\end{array}$ & $\begin{array}{c}\text { Average Power (MW) for } \\
\text { 90\% Depth of Discharge }\end{array}$ \\
\hline 0 & 81.1250 & 24.3902 \\
\hline 1 & 100.0000 & 73.1707 \\
\hline 2 & 100.0000 & 99.9390 \\
\hline 3 & 45.6251 & 100.0000 \\
\hline 4 & 0 & 100.0000 \\
\hline 5 & 0 & 100.0000 \\
\hline 6 & 0 & 92.6220 \\
\hline 7 & 0 & 48.7805 \\
\hline 8 & 0 & 6.0976 \\
\hline
\end{tabular}

In the case is which pumped storage is used for the storage device rather than NaS battery storage, the modeling can follow a similar process. The average power values that were obtained in Table 4-6 can also be obtained using pumped storage as the storage device. With new developments in pumped storage such as next generation variable speed pumped storage power stations, the ability to control the charging and discharging rate is quite flexible [8].

The purpose of this study is to show the effect that grid level energy storage has by reducing the load enough to eliminate the use of gas turbine generators. Both pumped storage and NaS are to be used and compared. Due to the fact that one focus of this study is a comparison between pumped storage and $\mathrm{NaS}$, and the fact that pumped storage can have quite flexible charging and discharging rates, it is a reasonable assumption to make that both the NaS batteries and pumped storage facility can have the same charging and discharging profiles. For this reason the charging and discharging profiles for the NaS batteries will also be used for pumped storage. 
Hourly Power Discharging Profile
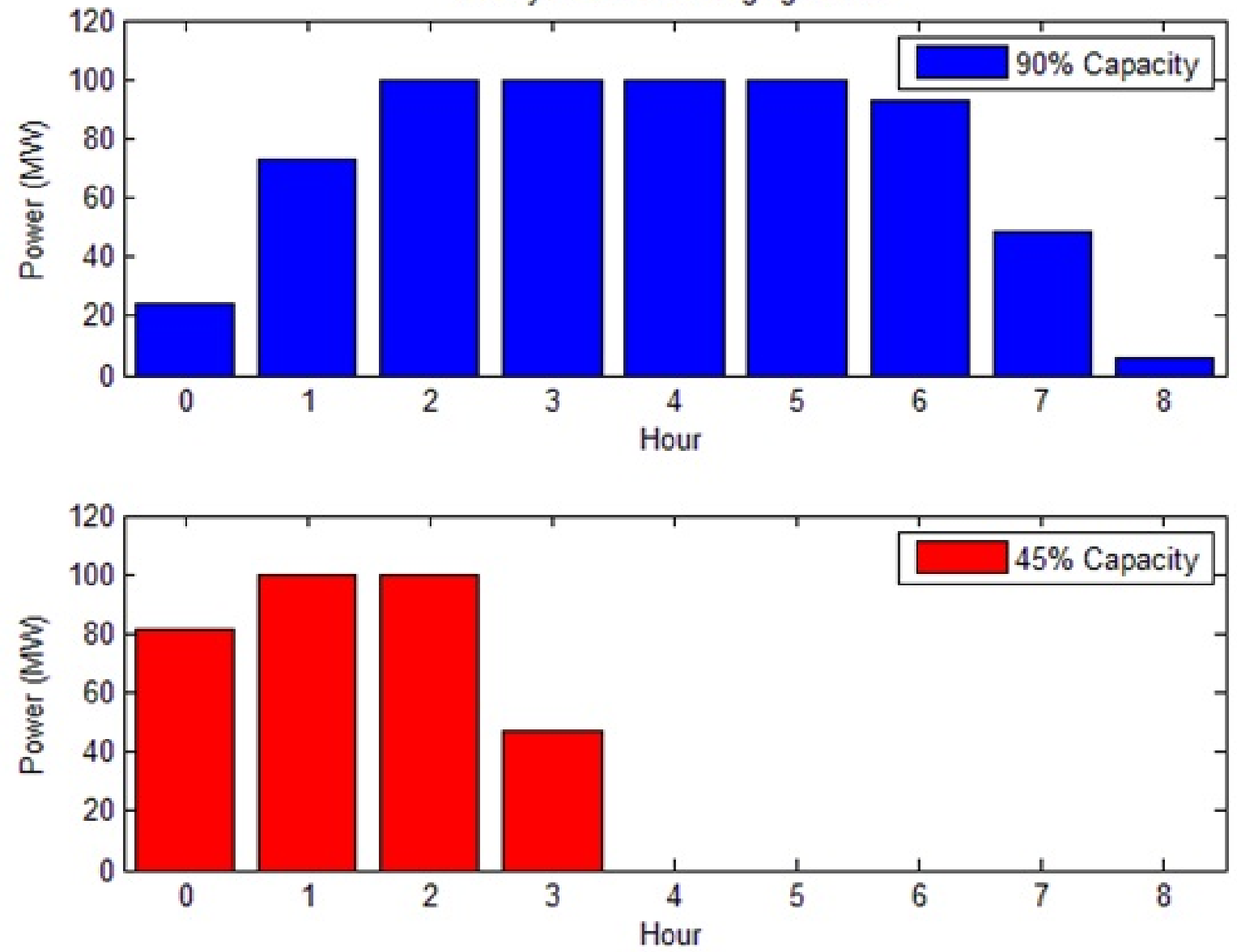

Figure 4-7: Average Power for Discharging Profiles 


\subsection{ALLOCATION OF STORAGE FOR LOAD LEVELING}

The energy storage devices that were discussed in the introduction to this chapter were modeled according to the techniques discussed in Section 4.4. It can be seen from Figure 4-2 that the system load is at its lowest during the early morning hours. These hours are the opportune time for the charging of storage. For this study the storage was charged between the hours of 0000 and 1000. The amount that was charged and the times that the charging took place was decided by using dynamic programming. For the NaS case the batteries had $120 \mathrm{MW}$ delivered to each unit for six hours and then 57.6 MW for one hour to charge the batteries to their full MWh capacity. The three commercial battery facilities were charged from 0000 to 0700 one residential facility was charged from 0200 to 0900 and the other residential facility from 0300 to 1000. The charging profile for the NaS case was mimicked for the pumped storage case.

The power that was stored by each of the units was then allocated using the dynamic programming method of optimization that was discussed in Section 3.2. The goal of the optimization was to minimize the average change in system demand per hour while maintaining a maximum change less than or equal to $300 \mathrm{MW}$. Equation (4.15) was used to calculate the average change in power per hour.

$$
\text { average power change }=\frac{\sum_{i=0}^{22}\left|P_{\text {load }}[i+1]-P_{\text {load }}[i]\right|}{23}
$$

And the maximum slope change was calculated using (4.16).

$$
\text { greatest power change }=\max \left(\left|P_{\text {load }}[i+1]-P_{\text {load }}[i]\right|\right) \quad \text { for } 0 \leq i \leq 22
$$


Dynamic programming was used along with the MATLAB code in the appendix to optimize the allocation of energy storage. For the case in which the batteries were using $90 \%$ depth of discharge a rough estimation to the optimum solution can be found visually by looking at Figure 4-2. The commercial load is consistently high from hour 1000 through the evening at about hour 2200. The residential load is high in the evening when people are all home from work. Using this observation it is fairly obvious that the most optimum solution to allocating the stored energy would be to discharge the commercial sector batteries so that the maximum discharging power of the batteries happened around the 1100 hour and to discharge the residential sector batteries so that the maximum discharging power occurred around 1500 to 1700.

The problem with the $90 \%$ discharge is that it doesn't quite suit the double peak of the load. Due to the fact that there are two load peaks, discharging the batteries to $90 \%$ depth never reduces the maximum change in load below $300 \mathrm{MW}$. Therefore, in the case in which the batteries are discharged once daily to $90 \%$ depth of discharge, the gas turbine generator must be used to accommodate the maximum change in the load.

The result was much better for the case in which the batteries were using two discharges of $45 \%$ each to allocate the stored energy. It was much easier to concentrate on reducing only the peaks due to the fact that there is a double peak in the load and there are two available discharges while using the $45 \%$ depth of discharge. The greatest change in power was able to be reduced to $300 \mathrm{MW}$ using this method. Table 4-7 illustrates the effect that the allocation of the battery storage had on the load and the charging and discharging daily profile is illustrated in Figure 4-8. In Figure 4-8 negative MW represent the battery charging power and positive MW represent battery discharging power. 
Table 4-7: Effect of Storage on the System Load

\begin{tabular}{|c|c|c|}
\hline Discharge Depth & $\begin{array}{c}\text { Average Change in Power } \\
\text { (MW) }\end{array}$ & $\begin{array}{c}\text { Maximum Change in Power } \\
\text { (MW) }\end{array}$ \\
\hline $0 \%$ & 119.565 & 500.000 \\
\hline $45 \%$ & 130.772 & 300.000 \\
\hline $90 \%$ & 126.426 & 320.448 \\
\hline
\end{tabular}

The first and primary goal of this optimization was to reduce the maximum change in power for any particular time step a value of $300 \mathrm{MW}$ or less. Once the maximum change in power was reduced to a value less than or equal to $300 \mathrm{MW}$ the focus of the optimization then shifts to reducing the average change in power. The flatter that the load profile is the cheaper the cost of the thermal generating units is due to the quadratic nature of their fuel cost curves. The less the speed of the generators has to be changed to meet changes in the load profile also leads to lower maintenance costs.

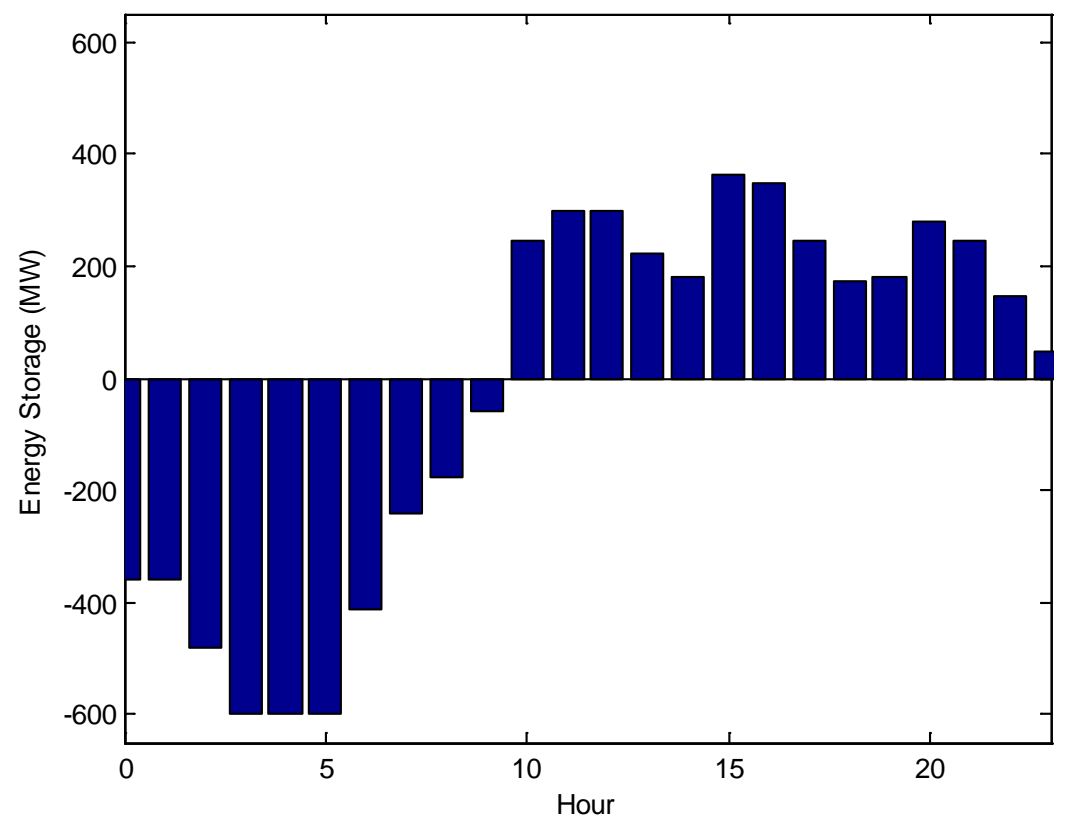

Figure 4-8: Charging and Discharge Profile for Energy Storage

Figure 4-9 illustrates the effect of the allocation of the storage on the load. 
Daily Demand Curve With No Storage

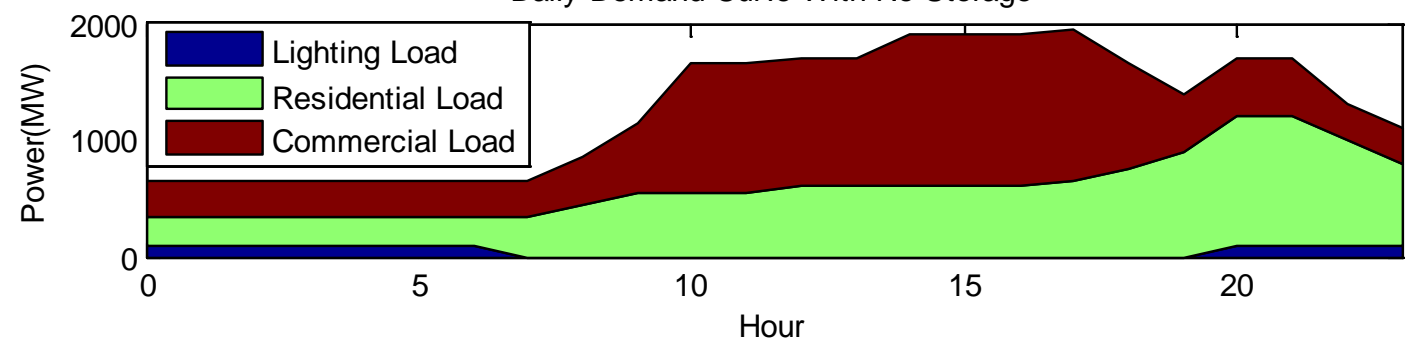

Daily Demand Curve Using Storage With 45\% Depth of Discharge

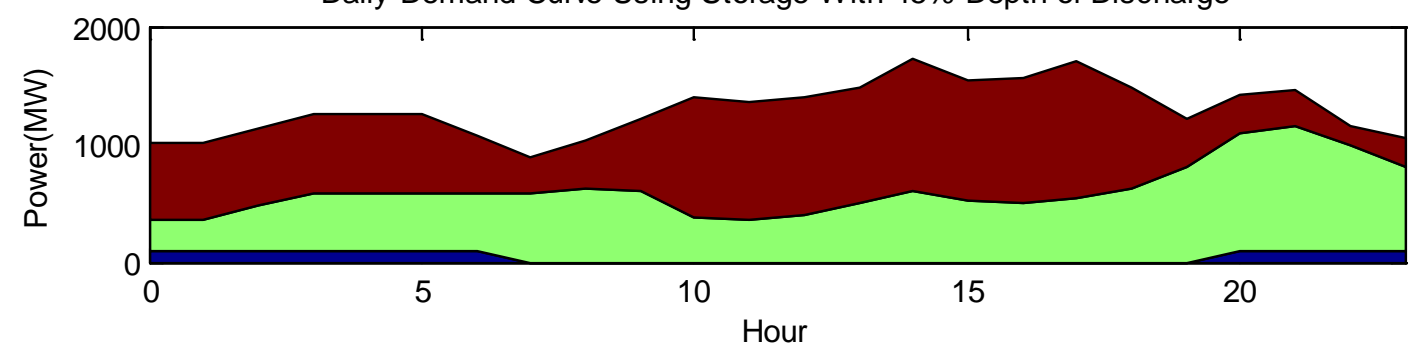

Daily Demand Curve Using Storage With 90\% Depth of Discharge

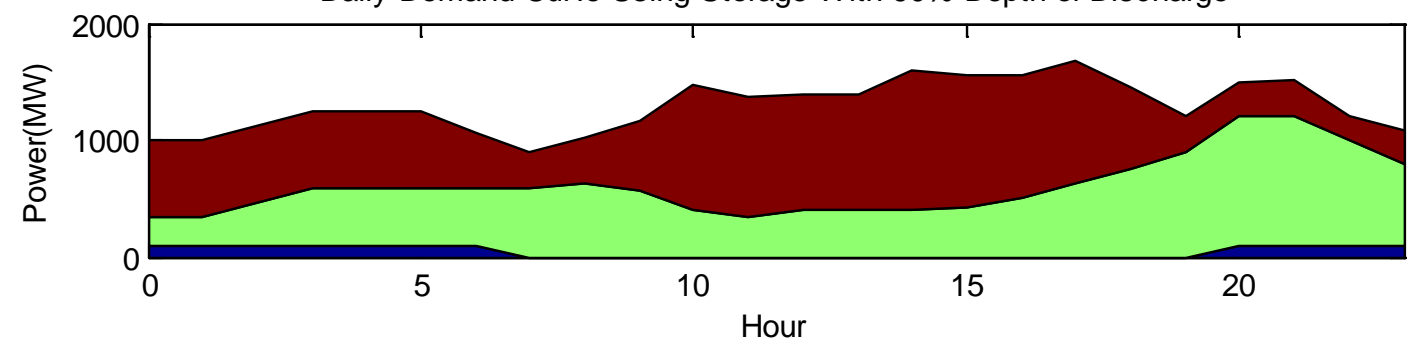

Figure 4-9: Load Profile Comparisons with the Integration of Storage 
Table 4-8 gives the operation of the battery storage units for optimal case for both $45 \%$ depth of discharge and $90 \%$ depth of discharge. In this table Cmr is the abbreviation for commercial, Rsi is the abbreviation for residential and Dis is the abbreviation for discharge. It should be noted that the second discharge for the $45 \%$ depth of discharge is always greater or equal to five hours after the first discharge as per constraints.

Table 4-8: Discharging Times for the Commercial and Residential Batteries

\begin{tabular}{|c|c|c|c|c|c|c|c|c|c|c|}
\hline $\begin{array}{c}\text { Depth of } \\
\text { Discharge }\end{array}$ & $\begin{array}{c}\text { Cmr1 } \\
\text { Dis 1 }\end{array}$ & $\begin{array}{c}\text { Cmr2 } \\
\text { Dis 1 }\end{array}$ & $\begin{array}{c}\text { Cmr3 } \\
\text { Dis 1 }\end{array}$ & $\begin{array}{c}\text { Rsi1 } \\
\text { Dis 1 }\end{array}$ & $\begin{array}{c}\text { Rsi2 } \\
\text { Dis 1 }\end{array}$ & $\begin{array}{c}\text { Cmr1 } \\
\text { Dis 2 }\end{array}$ & $\begin{array}{c}\text { Cmr2 } \\
\text { Dis 2 }\end{array}$ & $\begin{array}{c}\text { Cmr3 } \\
\text { Dis 2 }\end{array}$ & $\begin{array}{c}\text { Ris1 } \\
\text { Dis 2 }\end{array}$ & $\begin{array}{c}\text { Rsi2 } \\
\text { Dis 2 }\end{array}$ \\
\hline $45 \%$ & 1400 & 1300 & 1000 & 1000 & 1000 & 2000 & 1900 & 1500 & 1800 & 1500 \\
\hline $90 \%$ & 0900 & 0900 & 1000 & 1500 & 1500 & n/a & n/a & n/a & n/a & n/a \\
\hline
\end{tabular}

\subsection{SETTING UP THE ECONOMIC DISPATCH PROBLEM}

The techniques that were discussed in Section 3.1 were used with the goal of making an economic analysis of the effect of load leveling. MATLAB was used to compute the economic dispatch of the system load for every hour listed in Table 4-4. The results of this analysis are described in detail in the next chapter.

As was discussed in Section 3.1 the optimum dispatch of the thermal generator units described in Section 4.1 will be found by using Lagrange multipliers. For the use of Lagrange multipliers there must be an objective equation and a constraint equation. The objective equation that is used for the economic dispatch problem is the sum of the fuel cost curves and is given in (4.17) 


$$
F_{\text {total }}\left(P_{\text {coal }}, P_{\text {oil }}, P_{\text {gas }}\right)=F_{\text {coal }}\left(P_{\text {coal }}\right)+F_{\text {oil }}\left(P_{\text {oil }}\right)+F_{\text {gas }}\left(P_{\text {gas }}\right)
$$

The constraint equation that is used for the economic dispatch problem is the sum of the output powers for the coal, oil and gas thermal generation units is equal to the system load and is given in (4.18)

$$
P_{\text {load }}=P_{\text {coal }}+P_{\text {oil }}+P_{\text {gas }}
$$

This yields the Lagrangian equation as follows

$$
\ell\left(P_{\text {coal }}, P_{\text {oil }}, P_{\text {gas }}, \lambda\right)=F_{\text {coal }}\left(P_{\text {coal }}\right)+F_{\text {oil }}\left(P_{\text {oil }}\right)+F_{\text {gas }}\left(P_{\text {gas }}\right)+\lambda\left(P_{\text {load }}-P_{\text {coal }}-P_{\text {oil }}-P_{\text {gas }}\right)
$$

Taking the partial derivative of the Lagrangian with respect to each of the powers yields the system of equations in (4.20).

$$
\frac{\partial \ell}{\partial P_{i}}=\frac{d F_{i}}{d P_{i}}-\lambda=0
$$

Where $i$ is equal to coal, oil or gas. Taking the derivatives of the fuel cost curves for the thermal generator units described in (4.5)-(4.7) yields (4.21)-(4.23).

$$
\begin{gathered}
\frac{d F_{\text {coal }}}{d P_{\text {coal }}}=7.92+0.003124 P_{\text {coal }} \\
\frac{d F_{\text {oil }}}{d P_{\text {oil }}}=7.97+0.0096 P_{\text {oil }}
\end{gathered}
$$




$$
\frac{d F_{\text {gas }}}{d P_{\text {gas }}}=10.909+0.0090 P_{\text {gas }}
$$

Equations (4.21)-(4.23) are then used to implement the system of equations that is given by equation (3.12) giving (4.24)-(4.26).

$$
\begin{gathered}
7.92+0.003124 P_{\text {coal }}=\lambda \\
7.97+0.0096 P_{\text {oil }}=\lambda \\
10.909+0.0090 P_{\text {gas }}=\lambda
\end{gathered}
$$

Rearranging (4.24)-(4.26) and implementing the constraint equation yields the system of equations given in (4.27)-(4.30).

$$
\begin{gathered}
0.003124 P_{\text {coal }}-\lambda=-7.92 \\
0.0096 P_{\text {oil }}-\lambda=-7.97 \\
0.0090 P_{\text {gas }}-\lambda=-10.909 \\
P_{\text {coal }}+P_{\text {oil }}+P_{\text {gas }}=P_{\text {load }}[k]
\end{gathered}
$$

Where $P_{\text {load }}$ is a function of discrete time and $k$ represents the hour of the day. Equations (4.27)(4.30) can be rewritten in matrix form as follows in (4.31).

$$
\left[\begin{array}{cccc}
0.003124 & 0 & 0 & -1 \\
0 & 0.0096 & 0 & -1 \\
0 & 0 & 0.0090 & -1 \\
1 & 1 & 1 & 0
\end{array}\right]\left[\begin{array}{c}
P_{\text {coal }} \\
P_{\text {oil }} \\
P_{\text {gas }} \\
\lambda
\end{array}\right]=\left[\begin{array}{c}
-7.92 \\
-7.97 \\
-10.909 \\
P_{\text {load }}[k]
\end{array}\right]
$$


Solving (4.31) by taking the inverse of the $4 \times 4$ square matrix yields the following matrix equation given in (4.32).

$$
\left[\begin{array}{c}
P_{\text {coal }} \\
P_{\text {oil }} \\
P_{\text {gas }} \\
\lambda
\end{array}\right]=\left[\begin{array}{cccc}
0.003124 & 0 & 0 & -1 \\
0 & 0.0096 & 0 & -1 \\
0 & 0 & 0.0090 & -1 \\
1 & 1 & 1 & 0
\end{array}\right]^{-1}\left[\begin{array}{c}
-7.92 \\
-7.97 \\
-10.909 \\
P_{\text {load }}[k]
\end{array}\right]
$$

Equation (4.32) was used to calculate the hour by hour economic dispatch of for the system load without the use of battery storage for peak shaving. Incorporating the battery storage changes the constraint equation given in (4.18). Equation (4.18) needs the addition of a storage equation to calculate the economic dispatch of the load with load leveling. For the NaS case the storage equation is as given in (4.33).

$$
P_{\text {storage }}[k]=P_{C m r 1}[k]+P_{C m r 2}[k]+P_{C m r 3}[k]+P_{R s i 1}[k]+P_{R s i 2}[k]
$$

Where Cmr stands for commercial and Rsi stands for residential. This equations represent the power of all five batteries as a function of discrete time where $k$ is in hours. The power value of the batteries can either be positive or negative based on the operational mode of the batteries. If the batteries are charging then the power values for that hour are negative, likewise, if the batteries are discharging then the power values for that hour are positive. For the pumped storage $P_{\text {storage }}[k]$ is given by the charging and discharging profile given in Figure 4-8. Implementing (4.33) into the constraint equation given in (4.18) gives the new constraint equation given in (4.34).

$$
P_{\text {load }}-P_{\text {storage }}=P_{\text {coal }}+P_{\text {oil }}+P_{\text {gas }}
$$


The solution to the economic dispatch problem with the integration of grid level energy storage for the application of load leveling can then be written in matrix form using the new constraint equation as follows in (4.35)

$$
\left[\begin{array}{c}
P_{\text {coal }} \\
P_{\text {oil }} \\
\lambda
\end{array}\right]=\left[\begin{array}{ccc}
0.003124 & 0 & -1 \\
0 & 0.0096 & -1 \\
1 & 1 & 0
\end{array}\right]^{-1}\left[\begin{array}{c}
-7.92 \\
-7.97 \\
P_{\text {load }}[k]-P_{\text {stor }}[k]
\end{array}\right]
$$

The objective of this economic dispatch problem is to ensure that the optimal solution is indeed a minimal cost solution. To check that the solution to the economic dispatch problem is a minimum, the second derivative test for the cost curves is used. Taking the second derivative of (4.1)-(4.3) yields (4.36)-(4.38).

$$
\begin{aligned}
\frac{d^{2} F_{\text {coal }}}{d P_{\text {coal }}^{2}} & =0.003124 \\
\frac{d^{2} F_{\text {oil }}}{d P_{\text {oill }}^{2}} & =0.0096 \\
\frac{d^{2} F_{\text {gas }}}{d P_{\text {gas }}^{2}} & =0.0090
\end{aligned}
$$

It is clear from (4.36)-(4.38) that the second derivatives are positive from all possible output power values. This means that setting the first derivative equal to zero could only yield a minimal solution. 


\subsection{ANALYSIS AND RESULTS}

The problem that was described in Chapter 4.0 was carried out with the intent to analyze both the case in which gas turbines are used to accommodate drastic changes in the load and the case in which large grid scaled energy storage devices were used instead of the gas turbines.

\subsection{ECONOMIC DISPATCH SOLUTION WITHOUT ENERGY STORAGE}

The optimum economic dispatch for the load that was modeled in Section 4.3 was calculated using the cost vs. power curves that were given in Section 4.1. Scientific computing was used to calculate this economic dispatch for the system load in increments of one hour.

The economic dispatch that was calculated had to be analyzed to see if it met the unit commitment constraints that were given in Section 0. There were many hours in which the economic dispatch yielded a negative power value for the gas turbine generator. This was as expected due to its very high cost. For these hours the gas turbine generators were run in the spinning reserve mode. Setting the gas turbine generators to spinning reserve mode reduces the $4 \times 4$ matrix in (4.29) and (4.30) to a $3 \times 3$ matrix by eliminating the power generated by gas. Table 5-1 gives the total system load and the power that was generated by each individual generator to supply it. The change in power per time step had to be analyzed particularly for the coal and oil generators. These generators were constrained to changing no more than $150 \mathrm{MW}$ 
per time step. However, there were several time steps in which the coal generator needed to change by more than $150 \mathrm{MW}$ per time step for the most economical solution. In these cases the coal generator was set to its maximum change of $150 \mathrm{MW}$ and the economic dispatch was calculated by reducing the $4 x 4$ matrix in (4.29) and (4.30) to a $3 \times 3$ matrix in equation by eliminating the power generated by coal. Also, there were several hours in which this the solution to this economic dispatch problem yielded a solution in which the power generated by oil changed by more than 150 MW. For these cases the oil generator was set to its maximum change of $150 \mathrm{MW}$. With both the gas and oil generators set to their maximum change per time step the remaining power demanded by the load had to be delivered by the gas turbine generator. If the remaining power demanded by the load was greater than the minimum power constraint of the gas turbine generator then the gas turbine generator was set to that value. If on the other hand, the remaining power demanded by the load was less than the minimum power constraint of the gas turbine generator then the gas turbine generator was set to its minimum value and the economic dispatch was recalculated.

The early morning hours have a load which is much less than when the load peaks in the evening. The coal and oil generators were running at a very high power output for the load peak but had to be brought down to meet the early morning demand. From hour 2000 the coal generator was reduced by the maximum power change through hour 2300 so that the system demand could be met for the early morning hours. The oil generator was reduced from hour 2200 by less than the maximum in order to meet the system demand of the early morning hours. These adjustments were made possible by the supplemental power delivered by the gas turbine generator. The gas turbine generator was shut down into spinning reserve mode at hour 0000 because it would not be needed for the early morning hours. Although the gas turbine generator 
was not needed for hours 0800 and 0900 , it was given a hot start at hour 0700 just in case there were drastic changes during rush hour. Table 5-1 and gives the power generated by each generator for every hour. The power outputted by each of the generators is illustrated in Figure 5-1. It can be seen from this figure that there are no changes for the coal or oil fired generators that are greater than the maximum possible change of 150 MW per time step. All large power changes are covered by the gas turbine generators. It can also be seen from the figure that the coal and oil generators are brought down slowly at the end of the evening hours to meet the low early morning demand. 
Table 5-1: Power Distribution for Generators without Energy Storage

\begin{tabular}{|l|l|l|l|l|}
\hline Hour & $\begin{array}{c}\text { Coal Generation } \\
(\mathbf{M W})\end{array}$ & $\begin{array}{c}\text { Oil Generation } \\
\mathbf{( M W}\end{array}$ & $\begin{array}{c}\text { Gas Generation } \\
\mathbf{( M W} \text { ) }\end{array}$ & $\begin{array}{c}\text { Total Load } \\
\mathbf{( M W} \mathbf{~}\end{array}$ \\
\hline 0000 & 490.87 & 159.13 & Hot Shut Down & 650.00 \\
\hline 0100 & 490.87 & 159.13 & spinning reserve & 650.00 \\
\hline 0200 & 490.87 & 159.13 & spinning reserve & 650.00 \\
\hline 0300 & 490.87 & 159.13 & spinning reserve & 650.00 \\
\hline 0400 & 490.87 & 159.13 & spinning reserve & 650.00 \\
\hline 0500 & 490.87 & 159.13 & spinning reserve & 650.00 \\
\hline 0600 & 490.87 & 159.13 & spinning reserve & 650.00 \\
\hline 0700 & 490.87 & 159.13 & Hot Start & 650.00 \\
\hline 0800 & 554.55 & 180.45 & 115.00 & 850.00 \\
\hline 0900 & 779.30 & 255.70 & 115.00 & 1150.00 \\
\hline 1000 & 929.30 & 405.70 & 315.00 & 1650.00 \\
\hline 1100 & 1079.30 & 434.16 & 136.54 & 1650.00 \\
\hline 1200 & 1229.30 & 355.70 & 115.00 & 1700.00 \\
\hline 1300 & 1286.55 & 298.45 & 115.00 & 1700.00 \\
\hline 1400 & 1337.69 & 430.10 & 132.22 & 1900.00 \\
\hline 1500 & 1337.69 & 430.10 & 132.22 & 1900.00 \\
\hline 1600 & 1337.69 & 430.10 & 132.22 & 1900.00 \\
\hline 1700 & 1367.58 & 439.83 & 142.59 & 1950.00 \\
\hline 1800 & 1217.58 & 317.42 & 115.00 & 1650.00 \\
\hline 1900 & 1067.58 & 217.42 & 115.00 & 1400.00 \\
\hline 2000 & 1067.58 & 367.42 & 265.00 & 1700.00 \\
\hline 2100 & 917.58 & 459.00 & 323.42 & 1700.00 \\
\hline 2200 & 767.58 & 415.63 & 116.79 & 1300.00 \\
\hline 2300 & 617.58 & 280.29 & 151.40 & 1100.00 \\
\hline
\end{tabular}




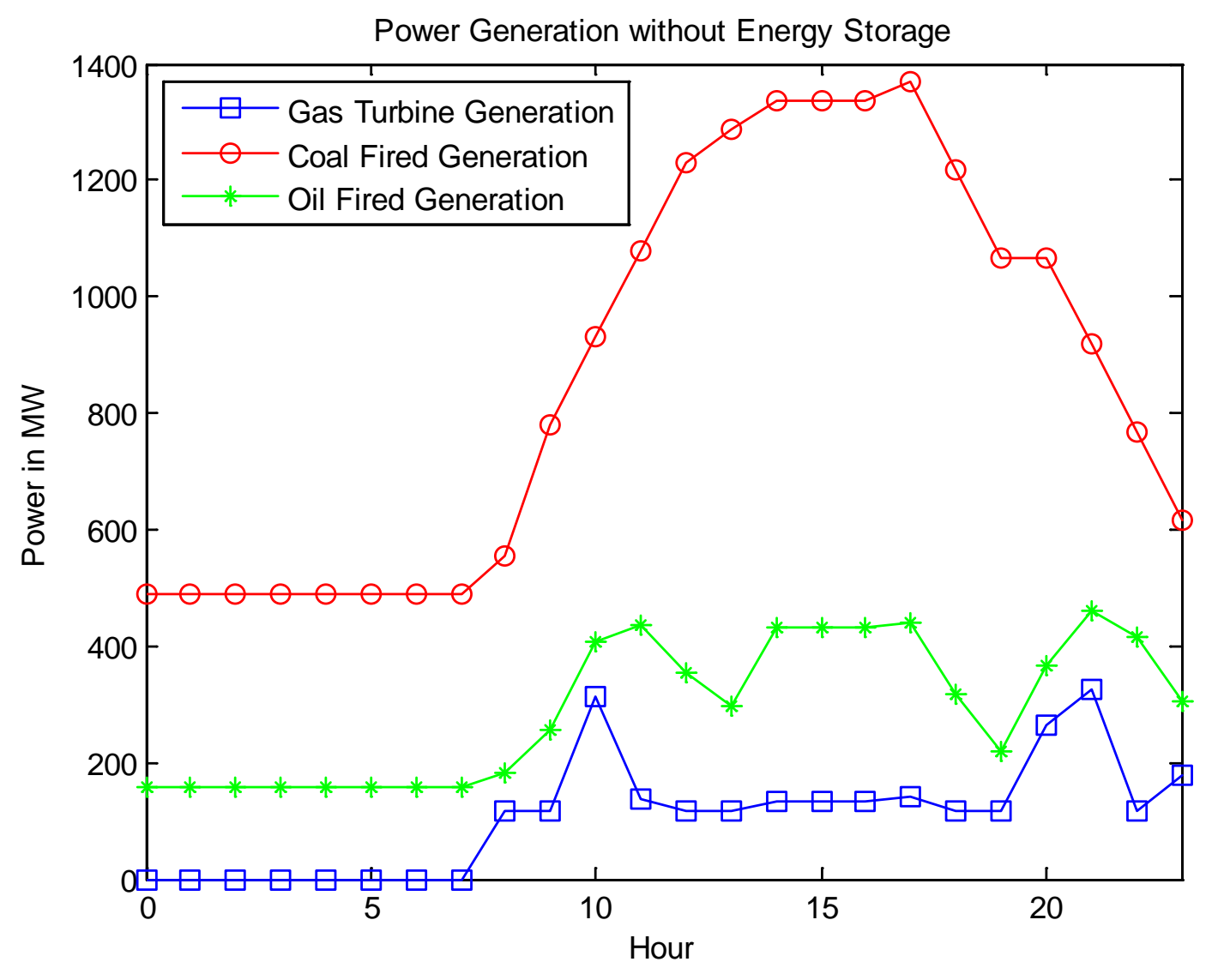

Figure 5-1: Power Distribution without Energy Storage 


\subsection{ECONOMIC DISPATCH SOLUTION WITH ENERGY STORAGE}

Energy storage was allocated using the methods described in Section 4.5 to reduce the maximum change in load to be less than or equal to $300 \mathrm{MW}$. With the allocation of storage, the maximum change in system load became equal to $300 \mathrm{MW}$.

As was discussed previously the goal of the use of storage for this study was to level the load enough so the use of gas turbine generators would not be needed. With the load leveled so that there is no step which exceeds the maximum change in power by the combined coal and oil fired generators, there is no need for the use of gas turbine generators in this system. The economic dispatch was calculated for each hourly time step for the load plus the energy storage. The solution to the economic dispatch problem produced values that did not fit the unit commitment constraints so the solution had to be re-dispatched according to these constraints. There were changes in the load that required the coal generator to change by more than the maximum value of $150 \mathrm{MW}$. For these hours the coal generator was set to the maximum change and was then subtracted by the load plus storage to give the oil fired power output for that hour.

The solution to the economic dispatch for each hour is given in Table 5-2. In this table the total load is equal to the total load that was given in Table 5-1 with the subtraction of the battery storage given in its respective column. Figure 5-2 illustrates the power outputted by coal and oil fired generators. It can be seen from this figure that there are no time steps in which either the coal or oil generator exceeds the maximum possible change in output power. 
Table 5-2: Power Distribution of Generators with Energy Storage

\begin{tabular}{|l|l|l|l|l|}
\hline Hour & $\begin{array}{c}\text { Coal Generation } \\
(\mathbf{M W})\end{array}$ & $\begin{array}{c}\text { Oil Generation } \\
\mathbf{( M W})\end{array}$ & Battery (MW) & $\begin{array}{c}\text { Total Load } \\
\mathbf{( M W )}\end{array}$ \\
\hline 0000 & 765.95 & 244.05 & -360.00 & 1010.00 \\
\hline 0100 & 765.95 & 244.05 & -360.00 & 1010.00 \\
\hline 0200 & 856.49 & 273.51 & -480.00 & 1130.00 \\
\hline 0300 & 947.03 & 302.97 & -600.00 & 1250.00 \\
\hline 0400 & 947.03 & 302.97 & -600.00 & 1250.00 \\
\hline 0500 & 947.03 & 302.97 & -600.00 & 1250.00 \\
\hline 0600 & 805.79 & 257.01 & -412.80 & 1062.80 \\
\hline 0700 & 675.42 & 214.58 & -240.00 & 890.00 \\
\hline 0800 & 773.76 & 234.23 & -177.60 & 1027.60 \\
\hline 0900 & 908.61 & 298.99 & -57.50 & 1207.60 \\
\hline 1000 & 1035.77 & 370.86 & 243.37 & 1406.63 \\
\hline 1100 & 1022.48 & 327.52 & 300.00 & 1350.00 \\
\hline 1200 & 1060.20 & 339.80 & 300.00 & 1400.00 \\
\hline 1300 & 1119.80 & 359.19 & 221.00 & 1479.00 \\
\hline 1400 & 1269.80 & 449.08 & 181.13 & 1718.88 \\
\hline 1500 & 1164.13 & 373.62 & 362.25 & 1537.75 \\
\hline 1600 & 1175.19 & 377.46 & 346.63 & 1553.37 \\
\hline 1700 & 1289.09 & 414.28 & 246.62 & 1703.37 \\
\hline 1800 & 1117.26 & 358.37 & 174.38 & 1475.62 \\
\hline 1900 & 967.26 & 251.68 & 181.13 & 1218.88 \\
\hline 2000 & 1074.44 & 344.43 & 281.13 & 1418.88 \\
\hline 2100 & 1100.47 & 352.90 & 246.62 & 1453.37 \\
\hline 2200 & 950.47 & 202.90 & 146.63 & 1153.37 \\
\hline 2300 & 800.47 & 252.90 & 46.63 & 1053.37 \\
\hline
\end{tabular}




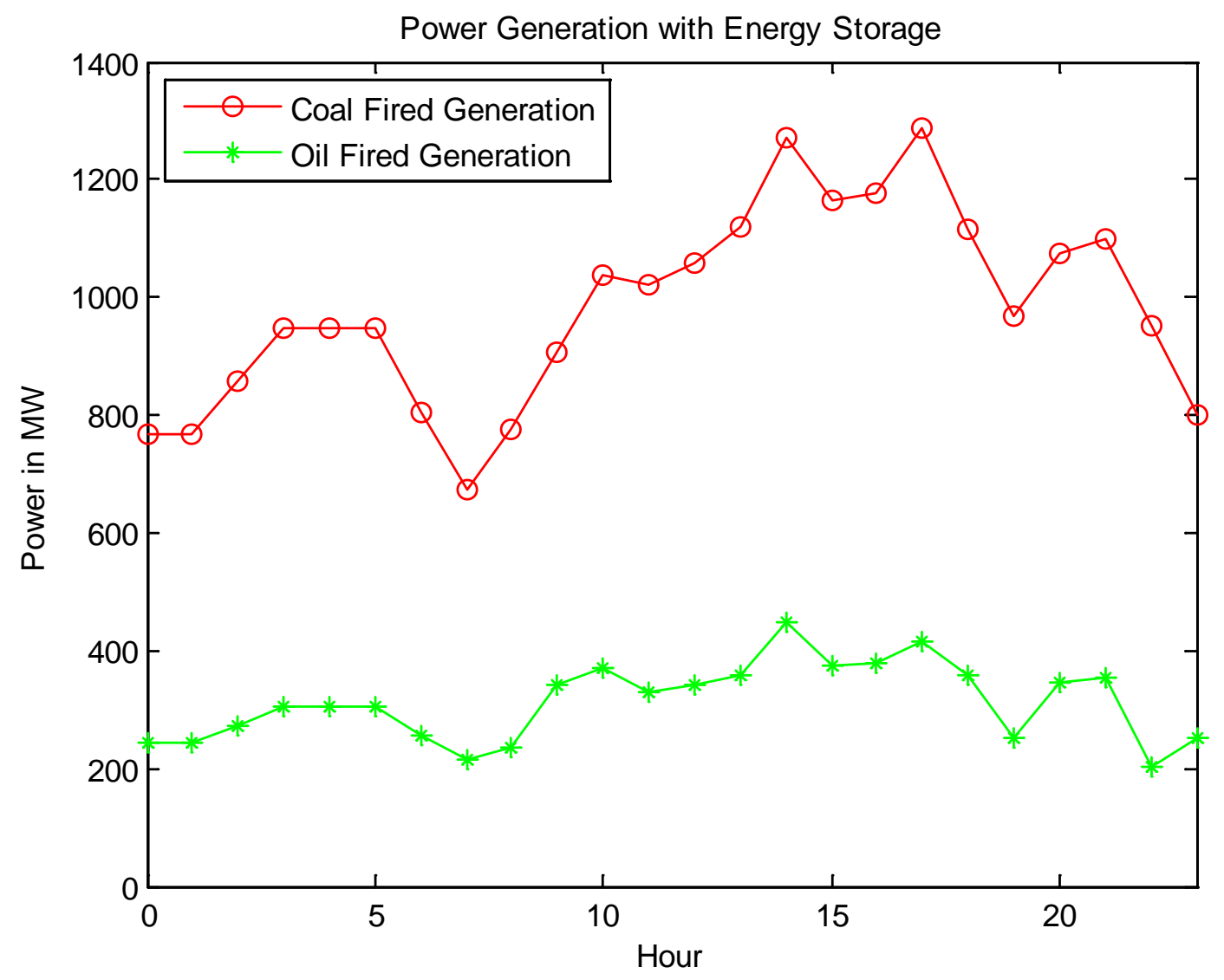

Figure 5-2: Power Distribution with Energy Storage 


\subsection{COST ANALYSIS}

This section covers the cost that it takes to run the generators to supply the load. Three cases which include the case in which there is no energy storage, the case where there is energy storage and the ideal case will be covered. The ideal case is such that the energy storage can be used to flatten the load completely so that it is at a constant value.

The data that was used for the fuel cost curves from [25] was generated in 1984 so the cost prices must be made up to date by including cost inflation of coal, oil and gas. Figure 5-3 through Figure 5-5 show the price of coal, oil and gas through the past [35]. The earliest data that is given for gas is January of 1991 so this date was used to calculate the price of inflation for all three forms of generation. The calculations are as follows in (5.1)-(5.3)

Coal Price Inflation:

Oil Price Inflation:

Gas Price Inflation:

$$
\frac{\$ 130 \text { per metric ton in } 2011}{\$ 40 \text { per metric ton in } 1991}=3.250
$$$$
\frac{\$ 107 \text { per barrel in } 2011}{\$ 30 \text { per barrel in } 1991}=3.567
$$

$$
\frac{\$ 160 \text { per cubic meter in } 2011}{\$ 43 \text { per cubic meter in } 1991}=3.720
$$

It can be seen from (5.1)-(5.3) that the price of gas inflated the most, the price of oil inflated the second most and the price of coal inflated the least with the inflation rate of all three sources of generation being in between 3.25 and 3.75. Due to the fact that all inflation ratios are very close and due to the fact that the inflation ratios agree with the way these forms of generation rank in 1984 . There is no need to change the output powers of the generators. 


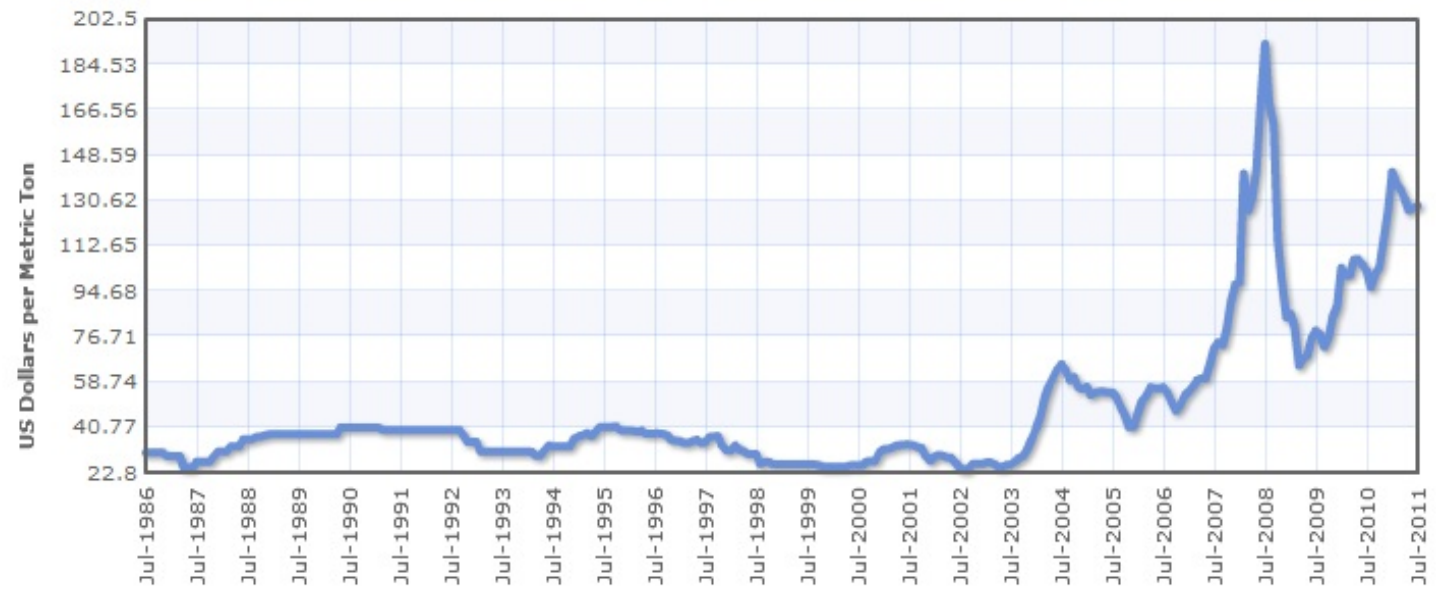

Figure 5-3: A History of Coal Prices [35]

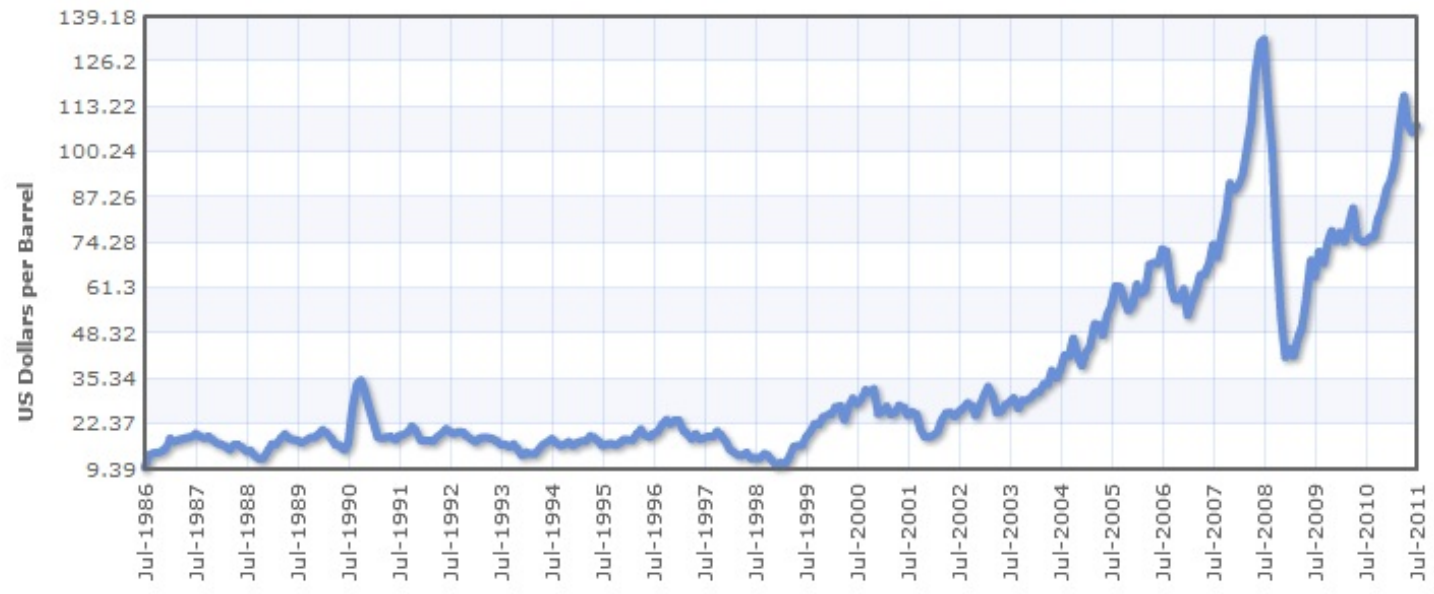

Figure 5-4: A History of Oil Prices [35]

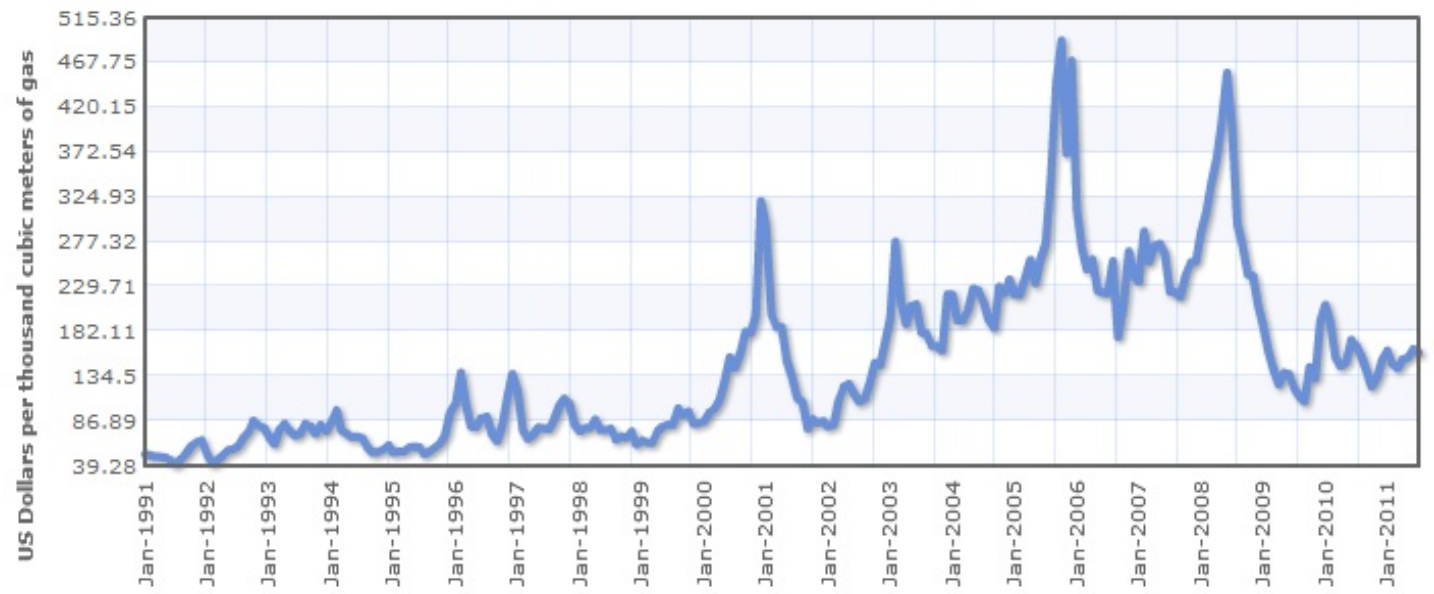

Figure 5-5: A History of Gas Prices [35] 


\subsubsection{The Case with No Energy Storage}

The thermal generator output power values that were given in Table 5-1 were used along with the fuel cost curves given in chapter four and the inflation cost rates at each hourly time step to calculate the cost of each form of generation. The cost of each form of generation and the total cost are given in Table 5-3.

Table 5-3: Daily Cost of Generation without Energy Storage

\begin{tabular}{|c|c|}
\hline Cost of Coal Generation: & $\$ 685,547$ \\
\hline Cost of Oil Generation: & $\$ 246,838$ \\
\hline Cost of Gas Generation: & $\$ 162,120$ \\
\hline Total Cost of Generation: & $\$ 1,094,398$ \\
\hline
\end{tabular}

\subsubsection{The Case with Energy Storage}

The thermal generator output power values that were given in table 5-2 were used along with the fuel cost curves given in chapter four and the inflation cost rates at each hourly time step to calculate the cost of each form of generation. The cost of each form of generation and the total cost are given in Table 5-4.

Table 5-4: Daily Cost of Generation with Energy Storage

\begin{tabular}{|c|c|}
\hline Cost of Coal Generation: & $\$ 770,127$ \\
\hline Cost of Oil Generation: & $\$ 261,360$ \\
\hline Cost of Gas Generation: & $\$ 0$ \\
\hline Total Cost of Generation: & $\$ 1,031,487$ \\
\hline
\end{tabular}




\subsubsection{The Ideal Case}

The average value of the system load was calculated and used as the load for each hour of the day. This simulates the absolute ideal case in which storage can be used to raise the load when it is below the average and lower the load when it is above the average so the load remains at its average value for the entire day. Of course, it is virtually impossible to completely flatten the load. But the ideal case is useful to measure how effective the load leveling procedure was. Table 5-5 gives the system load and the economic dispatch that satisfies it for each hour of the day.

Table 5-5: Hourly Economic Dispatch for the Ideal Case

\begin{tabular}{|c|c|c|c|}
\hline $\begin{array}{c}\text { Coal Generation } \\
(\mathbf{M W})\end{array}$ & $\begin{array}{c}\text { Oil Generation } \\
\mathbf{( M W )}\end{array}$ & $\begin{array}{c}\text { Gas Generation } \\
\mathbf{( M W )}\end{array}$ & Total Load (MW) \\
\hline 952.07 & 313.80 & 0 & 1265.87 \\
\hline
\end{tabular}

These thermal generator output power values were used along with the fuel cost curves given in chapter four and the inflation cost rates at each hourly time step to calculate the cost of each form of generation. The cost of each form of generation and the total cost are given in Table 5-6

Table 5-6: Cost of Generation for the Ideal Case

\begin{tabular}{|c|c|}
\hline Cost of Coal Generation: & $\$ 743,025$ \\
\hline Cost of Oil Generation: & $\$ 261,245$ \\
\hline Cost of Gas Generation: & $\$ 0$ \\
\hline Total Cost of Generation: & $\$ 1,004,270$ \\
\hline
\end{tabular}


The percent difference of total cost of generation for the load leveling case that was computed in this study and the ideal was calculated in (5.4).

$$
\% \text { differnce }=\frac{(1031487-1004270)}{\left(\frac{1031487+1004270}{2}\right)}=8.59 \%
$$

\subsubsection{Storage Cost}

The cost of storage was calculated for both the 600 megawatt, five battery NaS system as well as the 600 megawatt pumped storage facility.

\subsubsection{Cost of the NaS System}

In [1], current cost of NaS for grid level storage is given as a value of $\$ 1500$ per kilowatt. This value was used to calculate the cost of the battery storage that was used in this study. This calculation is given in (5.5).

$$
\frac{\$ 1500}{1 K W} \times \frac{1000 K W}{1 M W} \times \frac{120 M W}{1 \text { battery }}=\frac{\$ 180000000}{\text { battery }}
$$

The price of $\$ 180$ million per battery was multiplied by five to get the total cost for the five battery system of $\$ 900$ million.

\subsubsection{Cost of the Pumped Storage Facility}

The cost of the pumped storage facility was calculated by scaling the price of the Raccoon Mountain pumped storage facility given in [18]. The price of this facility per megawatt was calculated in (5.6). The dollar inflation rate was taken from [38]. 


$$
\frac{\$ 300000000}{1600 M W} \times \frac{\$ 3.47 \text { in } 2011}{\$ 1 \text { in } 1979}=\frac{\$ 650625}{M W}
$$

At a price of $\$ 650,625$ per megawatt the total price of a $600 \mathrm{MW}$ pumped storage facility comes out to about $\$ 390$ million.

\subsubsection{Economic Feasibility and Comparative Analysis}

The total cost of generation to supply the daily load described in Section 4.2 was $\$ 1,094,398$ and the cost of generation to supply the daily load with the addition of energy storage as was described in Section 4.5 was $\$ 1,031,487$. This leads to a total savings of \$62,911 per day and a total savings of $\$ 22,962,515$ per year.

The NaS system has a total battery life of fifteen years. Over the lifespan of the NaS batteries this system yields a total savings of $\$ 344,437,725$. While this is a great deal of money saved it is still less than half of the cost of the system. This does not mean that this technology is not useful however. The cycle life and efficiency of NaS systems are improving and the overall cost for NaS is being reduced [1,36]. The cycle life and efficiency must be improved and the cost must be reduced simultaneously for load leveling by means of grid level NaS systems to be lucrative. For example, if the efficiency is raised to $95 \%$ which can be done especially in a DC grid, the cycle life improved to 20 years rather than 15 and the cost of NaS storage reduced to $\$ 750$ per $\mathrm{kW}$ the total savings then becomes $\$ 545,359,731$ and the cost of the system becomes $\$ 450,000,000$ which yields a \$95,359,731 return on investment (ROI). 
The pumped storage system can have an operating life much longer than that of the battery system. For instance the Raccoon Mountain pumped-storage facility has been in operation since 1978 [18]. For the pumped storage plant which was considered in this study which had a total cost of \$390,000,000 it would take about seventeen years for a ROI. For a pumped storage facility in operation at least as long as the Raccoon Mountain facility there would be a total savings of over $\$ 367,763,000$.

The use of grid level energy storage by means of NaS batteries for the application of load leveling is still not economically viable. However, with efforts directed at reducing the cost and raising the efficiency and cycle life this technology could be viable in the not too distant future. Conversely, pumped storage has the potential for immediate economic gain when used for load leveling as long as there is a geographic location that suits the construction of a pumped storage facility. 


\subsection{CONCLUSION}

The potential economic benefit that grid level energy storage can provide is quite clear from this study. This can be seen by comparing the economic dispatch for the case in which there is no energy storage with the economic dispatch for the case where there is energy storage. There is the potential to save millions and even billions of dollars.

There are several benefits when using batteries for grid level energy storage for the application of load leveling. Batteries flatten the load so that the use of expensive gas turbine generators is not needed. As clean coal technology increases in efficiency the use of coal will produce much less harmful greenhouse gas emissions than gas turbine generators so the use of batteries for load leveling also has environmental benefits. They also reduce transmission losses due to the flexibility of their location. However, with all of the benefits that these batteries produce they are still much too expensive to be used as an economically viable solution. This does not mean that battery technology used for load leveling will never be a viable solution; it just means that it isn't right now. In the future as long as battery efficiency and cycle life are improved and the material and construction cost is reduced, there is room for a very large amount of economic growth by using batteries for load leveling. There is a lot of interest coming from both academia and industry in going to a DC grid. This same study performed on a DC

load would yield a much better result for NaS battery storage because it increases the efficiency a 
great deal. Currently solutions using battery storage tied to a DC grid are being developed $[39,40]$.

When used for load leveling, pumped storage shares nearly all of the same benefits that batteries have without the very large disadvantage of cost. Using pumped storage as a form of energy storage is relatively cheap. Pumped storage has a massive maximum power capacity that can range all the way up to the multi-gigawatt level. It can have a response time that can be as fast as seconds. With new developments in pumped storage such as the variable speed pumped storage unit the charging and discharging rate can be controlled. The money that can be saved by using pumped storage for the application of load leveling can yield a return on investment in a relatively short amount of time. The main downfall that pumped storage has is its limitation geographically. However, there is a great deal of locations available for the installations of pumped storage facilities.

Currently pumped storage is the only form of large grid level energy storage that can be economically beneficial. The locations that can support the installation of a pumped storage facility should be maximized in order to provide the greatest economic gain possible. Although at the present moment battery technology is not where it needs to be to provide this economic gain, the economic benefit that it can potentially have is clear as long as its efficiency and cycle life are increased and its cost is decreased. New battery types and chemical compositions should also be explored so the best possible battery option is found for the use of grid level applications. 


\subsection{FUTURE WORK}

The goal of this study was to analyze the use of grid level storage for the use of load leveling. In this study the charging and discharging was only considered by means of exchanging megawatts and losing megawatts to represent efficiency losses. However in an actual physical system it is not as simple as exchanging megawatts for the charging and discharging process. Current must flow into a battery in order for the battery to be charged.

One of the goals for future work is to model this system in terms of its physical layout. As one would imagine a 120 MW battery farm would be quite large and a fairly complex engineering design. There will be a lot of control theory that will have to be applied so that the batteries can be connected in parallel and charged and discharged as desired by the simulation used in this study. The design for each 120 MW battery farm will include twelve $10 \mathrm{MW}$ batteries that are connected to a single point bus in parallel. The appropriate voltage level for the bus should be investigated so that the charging and discharging current yields the desired power output. There is also the aspect of reactive power. This study was concerned more with the economics of large scaled battery storage so the load only had a real power component. As we

know, actual electric machinery will always have a real power component as well as a reactive power component. It would also be interesting to investigate the effects that this battery storage system has when the reactive power components are introduced. 
As was stated in the conclusion section there is a great deal of power loss caused by efficiency losses. One of the future goals of this project and for battery storage overall is to improve its efficiency. NaS batteries operate at a high temperature. Cooling systems which keep the operating temperature at a minimum in order to maximize efficiency can be investigated. Reducing the operating temperature will also increase the cycle life of the battery. Both increasing the efficiency and cycle life of batteries were objectives that make battery storage for the application of load leveling lucrative.

It was shown in this study that energy storage in the form of pumped storage can be lucrative today. Pumped storage is flexible in terms of its charging and discharging time and this flexibility is increasing even more with the integration of variable speed pumped storage facilities. The pumped storage facility that was used in this study can be modeled in terms of its discharging current as well as its voltage levels.

Storage types such as flow batteries were not used in this study due to the fact that they are in there infancy in terms of their technological maturity. There are multiple compositions of flow batteries that are very promising and could be a possible solution in the future. Flow batteries can be modeled and integrated into the economic dispatch problem that was done in this study to test their economic viability as there maturity increases. If flow batteries begin to show that they can become a solution which yields an economic gain they will also have to be modeled in terms of their voltage level as well as charging and discharging currents and the controls that will have to be implemented to achieve large quantities of power.

CAES is also in its early stages of development. Generation one CAES facilities, which are the only ones in current commercial operation, still have efficiency losses and gives off greenhouse gas emissions. Generation two CAES facilities are much more efficient and give off 
fewer emissions and are more efficient than the generation one facilities. The generation three CAES facilities give off zero emissions. The generation two and generation three facilities are in their early stages of development and were not used in this study. However, as the technology improves, especially for the generation three unit, it would be beneficial to study CAES for the use of load leveling.

Other forms of grid level energy should be studied as they develop. It is currently impossible to reach the ideal case of load leveling with current storage means due the nature of their charging and discharging profiles. However, super capacitors and SMES have discharge times that are in the seconds. These extremely fast discharging times will allow for a much flatter load than what can be achieved with slower discharging times. A future study of these storage methods could be beneficial as well. 


\section{BIBLIOGRAPHY}

[1] A. Nourai, "Installation of the First Distributed Energy Storage System (DESS) at American Electric Power”, A Study for the DOE Energy Storage Systems Program, Sandia Report, SAND2007-3580,Unlimited Release, Printed June 2007

[2] “Control of the National Grid”, November 2006, [online], Available: http://en.wikipedia.org /wiki/Control_of_the_National_Grid

[3] NGK Insulators, LTD., “NaS Batteries”, [online], Available: http://www.ngk.co.jp/english/ products/power/nas index.html

[4] P. Davidson, “New Battery Packs Powerful Punch”, USA Today, [online], Available: http:// www.usatoday.com/money/industries/energy/2007-07-04-sodium-battery_N.htm

[5] NGK Insulators LTD, Video on NaS Battery Storage, [online], Available: http://www.ngk. co.jp/english/products/power/nas/movie/movie_nas_english.html

[6] EPRI, “Energy Storage Technology Options, A White Paper on Applications, Cost and Benefits”, Final Report, December 2010

[7] Bito, A.; , "Overview of the sodium-sulfur battery for the IEEE Stationary Battery Committee," Power Engineering Society General Meeting, 2005. IEEE , vol., no., pp. 1232- 1235 Vol. 2, 12-16 June 2005

[8] J. Janning, A. Schwery, “Next Generation Variable Speed Pump-Storage Power Stations”

[9] ”Sodium-Sulfur Battery', June 2004, [online], Available: http://en.wikipedia.org/wiki/ Sodium $\%$ E2\%80\%93sulfur_battery

[10] Australian Government, Department of the Environment and Heritage, "Used Lead Acid Batteries”, August 2005, [online], Available: http://www.environment.gov.au/ settlements/chemicals/hazardous-waste/publications/pubs/lead-acid-fs.pdf

[11] “Lead-Acid Battery”, March 2003, [online], Available: http://en.wikipedia.org/wiki/Leadacid_battery

[12] Progressive Dynamics, Inc. “Battery Basics”, [online], Available: http://www. progressivedyn.com/battery_basics.html 
[13] New Scientist: The global science and technology weekly, "How Long Will It Last”, May 26, 2007, ISN 0262-4079

[14] A. Price, Member of the Board of Directors of Energy Storage Association, "Technologies for Energy Storage-Present and Future: Flow Batteries”, 2000, IEEE

[15] Ecovoltz, "How They Work, Flow Battery”, 2010 Ecovoltz Inc, [online], Available: http:// www.ecovoltz.com /flow-battery/flow-battery-basics/

[16] M. Skyllas-Kazacos, "An Historical Overview of the Vanadium Redox Flow Battery Development at the University of New South Wales, Australia", University of New South Wales, [online], Available: http://www.ceic.unsw.edu.au/centers/vrb/overview.htm

[17] Dominion, “Bath County Pumped Storage Station”, [Online], Available: http://www.dom.com/about/stations/hydro/bath-county-pumped-storage-station.jsp

[18] Tennessee Valley Authority, “The Mountain Top Marvel”, [online], Available: http://www. tva.gov/heritage/mountaintop/index.htm

[19] NASA John Glenn Research Center, "Sodium Sulfur Battery Schematic”, [online], Available: http://en.wikipedia.org/wiki/File:NaS_battery.jpg

[20] Cochran, A.M.; Isles, D.E.; Pope, I.T.; , "Development of pumped storage in a power system," Electrical Engineers, Proceedings of the Institution of , vol.126, no.5, pp.433438, May 1979

[21] ClimateTechWiki, A clear technology platform, "Energy Storage: Compressed Air (CAES)”, [online], Available: http://climatetechwiki.org/technology/jiqweb-caes

[22] M. Nakhamkin, “CAES Bottom Cycle Concept”, 2010, [online], Available: http:Iwww. espcinc.com

[23] Taylor, J.; Halnes, A.; , "Analysis Of compressed air energy storage," PCIC Europe 2010 Conference Record , vol., no., pp.1-5, 15-17 June 2010

[24] “Gradient”, August 2001, [online], Available: http://en.wikipedia.org/wiki/Gradient

[25] Wood, Allen J., Wollenberg Bruce F., "Power Operation, Generation, and Control”, Wiley, 1984

[26] "Comparison of the Economic Dispatch Solutions With and Without Losses”, A. Merev, Tubitak-Ume High Voltage Lab

[27] S. Dasgupta, C.H. Papadimitriou, U.V. Vazirani, "Dynamic Programming", http://www.cs.berkeley.edu/ vazirani/algorithms/chap6.pdf

[28] A. Kaufman, “Graphs, Dynamic Programming and Finite Games”, Academic Press, 1967 
[29] “Dynamic Programming”, October 2002, http://en.wikipedia.org/wiki/Dynamic _programming

[30] R. Bellman, “Dynamic Programming” 1957, republished by Dover press, 2003

[31] O'Connor, R.; Reed, G.; Zhi-Hong Mao; Jones, A.K.; , "Improving renewable resource utilization through integrated generation management," Power and Energy Society General Meeting, 2010 IEEE , vol., no., pp.1-6, 25-29 July 2010

[32] European Environmental Agency, "Air Polution from Electricity-Generating Large Combustion Plants: An assessment of the theoretical emission reduction of $\mathrm{SO}_{2}$ and $\mathrm{NO}_{x}$ through implementation of BAT as set in BREFs", EEA Technical Report No. 4, 2008

[33]A. Gabbard, “Coal Combustion: Nuclear Resource or Danger”, [online], Available: http:// www.ornl.gov/info/ornlreview/rev26-34/text/colmain.html

[34] Gönen, Turan, "Electric Power Distribution System Engineering”, Taylor and Francis Group, LLC, 2008

[35] Index Mundi, “Commodity Prices”, [online], Available: http://www.indexmundi.com/ commodities/

[36] M. Kitner-Meyer, "Energy Storage for Variable Renewable Energy Resource Integration- A Regional Assessment for the Northwest Power Pool (NWPP)” [online], Available: http://energyenvironment.pnnl.gov/ei/pdf/Energy\%20storage\%20for\%20variable\%20ren ewable\%20energy\%20sources.pdf

[37] G. L. Kusic, "Allocation of Power in Medium Voltage DC Distribution Circuits", University of Pittsburgh

[38] U.S. Inflation Calculator, [online], Available: http://www.usinflationcalculator.com/

[39] Reed, G.F.; Grainger, B.M.; Korytowski, M.J.; Taylor, E.J.; , "Modeling, analysis, and validation of a preliminary design for a $20 \mathrm{kV}$ medium voltage DC substation," Energytech, 2011 IEEE , vol., no., pp.1-8, 25-26 May 2011

[40] Reed, Gregory F.; Grainger, Brandon M.; Bassi, Hussain; Taylor, Emmanuel; Mao, ZhiHong; Jones, Alex K.; , "Analysis of high capacity power electronic technologies for integration of green energy management," Transmission and Distribution Conference and Exposition, 2010 IEEE PES , vol., no., pp.1-10, 19-22 April 2010

[41] Golden Valley Electric Association, “Battery Energy Storage System”, [online], Available: http://www.gvea.com/energy/bess

[42] AES Energy Storage, “AES Energy Storage Announces First Grid-Scale Battery-Based Storage System to Commercially Operate as a Generator in United States”, [online], Available: http://www.aesenergystorage.com/news/aes-energy-storage-announces-firstgrid-scale-battery-based-storage-system-commercially-operate 